\title{
NUMERICAL AND EXPERIMENTAL INVESTIGATIONS FOR INSULATION PARTICLE TRANSPORT PHENOMENA IN WATER FLOW
}

ECKHARD KREPPER, GREGORY CARTLAND GLOVER, ALEXANDER GRAHN, FRANK-PETER WEISS

Forschungszentrum Dresden Rossendorf e.V., (FZD), Institute of Safety Research, P.O.Box 510119, D-01314 Dresden, Germany

SÖREN ALT, RAINER HAMPEL, WOLFGANG KÄSTNER, ALEXANDER KRATZSCH, ANDRE SEELIGER

University of Applied Science Zittau/Görlitz,

Theodor Körner Allee 16, D-02763 Zittau, Germany
a) 30 manuscript folios
b) 17 figures
c) 1 table

Corresponding author:

Eckhard Krepper

Tel.: ++49 3512602067

Fax: ++493512602383

E-mail: E.Krepper@fzd.de 


\begin{abstract}
The investigation of insulation debris generation, transport and sedimentation becomes more important with regard to reactor safety research for Pressurized and Boiling Water Reactors, when considering the long-term behaviour of emergency core coolant systems during all types of loss of coolant accidents (LOCA). The insulation debris released near the break during a LOCA incident consists of a mixture of a disparate particle population that varies with size, shape, consistency and other properties. Some fractions of the released insulation debris can be transported into the reactor sump, where it may perturb or impinge on the emergency core cooling systems.

Open questions of generic interest are for example the particle load on strainers and corresponding pressure drop, the sedimentation of the insulation debris in a water pool, its possible re-suspension and transport in the sump water flow. A joint research project on such questions is being performed in cooperation with the University of Applied Science Zittau/Görlitz and the Forschungszentrum Dresden-Rossendorf. The project deals with the experimental investigation and the development of Computational Fluid Dynamic (CFD) models for the description of particle transport phenomena in coolant flow. While the experiments are performed at the University Zittau/Görlitz, the theoretical work is concentrated at Forschungszentrum Dresden-Rossendorf.
\end{abstract}

In the present paper, the basic concepts for CFD modelling are described and experimental results are presented. Further experiments are designed and feasibility studies were performed.

\title{
KEYWORDS
}

CFD, two-fluid approach, fibre flow 


\section{INTRODUCTION}

In 1992, a safety relief valve inadvertently opened on a steam-line in the Barsebäck-2 nuclear power plant in Sweden. The steam jet stripped fibrous insulation from the adjacent piping systems. Part of the insulation debris was transported to the wetwell pool and this debris clogged the intact strainers of the drywell spray system about one hour after the start of the incident. Although the incident in itself was not serious, it revealed a weakness in the defense-in-depth concept, which under other circumstances could have led to the emergency core cooling system (ECCS) failing to provide recirculation water to the core.

Research and development efforts of varying degrees of intensity were launched in many countries. The corresponding knowledge bases were updated several times and several workshops were performed (see e.g. the first four references). The international activities were especially summarized in the report NUREG/CR-6808 (2003) of the USNRC, a model of fibre release under the influence of a jet, an empirical equation for the difference pressure at the sieve dependent on the fibre load and the respective results of specifically designed material loadings experiments were presented. All these activities reflect in most cases the view of regulators and utilities. The current paper reports about efforts to investigate the problem in more detail, particularly with the aim of CFD model development.

\section{JOINT RESEARCH PROJECT}

A joint research project performed in cooperation with University of Applied Science Zittau/Görlitz and Forschungszentrum Dresden-Rossendorf deals with the experimental investigation and the development of CFD models for the description of particle transport phenomena in coolant flow. The experiments are performed at the University Zittau/Görlitz and are mainly based on high-speed video observation and on Laser Doppler Velocimetry (LDV) respective to Particle Image Velocimetry (PIV). The theoretical work is concentrated 
at Forschungszentrum Rossendorf. CFD models are developed, implemented in the CFD code ANSYS CFX and tested against experiments.

The main topics of the project are

- Primary particle constitution: Experiments are performed to blast blocks of insulation material by steam under the thermal hydraulic conditions to be expected during a LOCA incident (i.e. at pressures up to $11 \mathrm{MPa}$ ). The material obtained by this method is then used as raw material for further experiments.

- Transport behaviour of fibres: The transport behaviour of the steam-blasted material is investigated in a water column by optical high-speed video techniques. The sinking velocities of the fibres are then used to derive the drag coefficients and other physical properties of the modelled fibre phase, which is necessary for the implementation of an adequate CFD simulation.

- Transport of fibres in a turbulent water flow: For these investigations, a narrow channel with a racetrack type configuration was used with defined boundary conditions. Laser PIV measurements and high-speed video were used for the investigation of the water flow-field and the fibre concentration. Besides the drag acting on the particles, the turbulent dispersion force plays an important role in determining the momentum exchanged between the water and the fibrous phase.

- Deposition and re-suspension of fibres: The deposition and re-suspension behaviour at low velocities was investigated by the same techniques and the narrow racetrack channel. Except that, in this case obstacles were inserted into the channel to change locally the flow regime. The experiments are designed to work with laser PIV measurement and high-speed video. CFD approaches consider the influence of the 
fibre material on the mixture viscosity and the dispersion coefficient on the transport of the solids.

- Effect of strainers: A test rig was used to study the influence of the insulation material loading on the pressure difference observed in the region of the strainers. A CFD model was developed that uses the approach of a porous body. Correlations from the filter theory known in chemical engineering are adapted to the experiments and are used to model the flow resistance depending on the particle load. This concept also enabled the simulation of a partially blocked strainer.

- Behaviour of a plunging jet in a large pool: By using high-speed video and laser (LDV and PIV) measurements, the progression of the momentum by the jet in the pool is investigated. Of special importance is the role that entrained gaseous bubbles play on disturbing the fluid and potentially influencing the fibre sedimentation and resuspension.

\section{MODELLING OF THE FIBRE TRANSPORT IN WATER}

\subsection{General concept for modelling the fibre transport}

The actual task of a numerical simulation is the determination of the fibre material mass finally deposited in certain geometry (the reactor sump) and of the fibre mass dragged by the water flow. Since the momentum transport in the liquid flow plays an important role, the problem is clearly a $3 \mathrm{D}$ problem and has to be solved by applying computational fluid dynamic (CFD) methods.

CFD codes describe fluid flows based on the solution of the conservation equations for mass, momentum and energy. CFD methods are distinguished by using different solution strategies for the basic equations and physical models to obtain closure. For the current study, 
two fundamentally different approaches are known: The application of the EulerianLagrangian or the Eulerian-Eulerian approach.

The first approach relies on the solution of the Navier Stokes equations for the continuous fluid phase and on the solution of the Lagrangian equations for each of the particles considered. The particles are modelled with a certain mass to impose the momentum exchange at the point locations of the particles. The flow field acts on each particle and influences the particle path. The particles in turn affect the turbulence quantities of the flow. A particle spectrum can be easily given as an inlet condition to account for the different particles found in the steam-blasted material. Models simulating the particle reflection, the erosion and the sedimentation at walls can also be applied to impose specific physical phenomena.

The Euler/Euler approach assumes that at least two fluids are continuously penetrating each other. The volume fraction of the fluids in each cell sums to unity. For each fluid, the full set of conservation equations is solved. Therefore, each fluid has a different velocity field. The mechanisms of the interaction of the fluids are the flow resistance modelled by momentum transfer, phase change modelled by mass transfer and heat conduction modelled by energy transfer. Whereas, the two latter interactions in the present problem are not relevant, the flow resistance is essential for the description of debris transport.

Compared to the Euler/Euler approach the Euler/Lagrangian approach requires a higher numerical effort, which can limit the applicability of the models for the solution of the practical question. 


\subsection{Modelling the fibre transport applying the Euler/Euler approach}

The particle transport using the Eulerian-Eulerian approach is described by the exchange of momentum between the two phases. For the case of dispersed spherical bubbles or spherical particles moving in a continuous fluid, the interacting forces between the two phases have the principle form:

$$
F_{D}=\frac{1}{2} n_{d} \rho_{c} A C_{D}\left|V_{r e l}\right| V_{r e l}
$$

where $n_{d}$ is the particle number density, $\rho_{c}$ the liquid density, $A$ the cross sectional area of the particle in the flow direction, $V_{\text {rel }}$ the relative velocity between the phases, and $C_{D}$ the drag coefficient. The drag coefficient depends on the particle Reynolds Number Re, which is defined as:

$$
R e=\frac{\rho_{c}\left|V_{r e l}\right| d_{d}}{\mu_{c}}
$$

where $\mu_{c}$ is the dynamic liquid viscosity and $d_{d}$ is the particle diameter.

For low velocities with Reynolds Numbers $<<1$ the viscous effects dominate the inertial effect, and the regime is designated as Stokes flow to give the drag coefficient as:

$$
C_{D}=24 / R e
$$

For higher velocities $\left(1000<\operatorname{Re}<1.2 \cdot 10^{5}\right)$ the inertial effects dominate the viscous effects resulting in turbulent motion where:

$$
C_{D}=0.44
$$

In the transition region $(0.1<\operatorname{Re}<1000)$, where both effects are of the same order of magnitude, we find for spherical particles the Schiller-Naumann correlation (Schiller and Naumann 1933): 


$$
C_{D}=\max \left[\frac{24}{\operatorname{Re}}\left(1+0.15 \operatorname{Re}^{0.687}\right), 0.44\right]
$$

Other authors e.g. Frank (2002), Haider and Levenspiel (1989) or Salman and Verba (1988) also consider the eccentricity of the particle in the transition region. Turney et al. (1995) describe the drag for rod like particles.

In the current study, a virtual particle is defined as a small ball of wool fibres that mostly consists of water. This is correct, as the water in the insulation wool ball moves with the virtual particle velocity. This is due to entrapment of the water and local forces binding the water to the particles. Therefore, the virtual particle density, $\rho_{F}$, found here is close to that of water (i.e. $1000 \mathrm{~kg} \mathrm{~m}^{-3}$ ), whereas the density of real dry fibres $\rho_{d}$ amounts to about $2800 \mathrm{~kg} \mathrm{~m}^{-3}$. The density difference of water and fibres in the gravity field results in the buoyancy force $F_{B}$ :

$$
F_{B}=n_{d} g V_{F}\left(\rho_{F}-\rho_{c}\right)
$$

The equality of buoyancy and drag forces yields the sinking velocity:

$$
V_{S}=\sqrt{\frac{4}{3} g \frac{\rho_{F}-\rho_{c}}{\rho_{c}} d_{F} \frac{1}{C_{D}}}
$$

Equation (7) has to be solved iteratively since the drag coefficient $C_{D}$ is Reynolds Number dependent. The share of fibres, $\alpha_{F}$, in the virtual particle can be calculated by

$$
\alpha_{F}=\frac{\rho_{F}-\rho_{c}}{\rho_{d}-\rho_{c}}
$$




\subsection{Turbulence dispersion}

Simulation of the motion of buoyant particles considering only the drag force described in chapter 3.2 will finally find all particles at the bottom of the fluid domain. The observation of fibres in a turbulent water flow however shows suspending and gliding fibres. In the current work the interaction of the turbulent water flow and the fibres was considered by a turbulent dispersion force. This force was originally developed to obtain a closure model for the Reynolds stresses in terms of the k- $\varepsilon$ turbulence model and the transport of the particles in the continuous phase. It is based on the spatial gradient of the parameter characterising local dispersed phase (either the volume fraction or average mass density). The coefficient was derived from the integrating the fluctuating terms of the instantaneous particle transport equation along the particles trajectory. It was assumed that the autocorrelation of the turbulence is an exponential function of the Lagrangian turbulence time-scale, $\beta_{\mathrm{c}}$. This led to equation (9) as the limit of the integral with respect to time is increased to infinity. The fluctuating turbulent velocities of the continuous phase can be obtained from the turbulent kinetic energy. This was because typical values of $C_{T D}$ were found to be the order of 1 for gas bubbles and 500 for smaller diameter particles when the ratio of the particle relaxation time, $\beta_{\mathrm{d}}$, to $\beta_{\mathrm{c}}$ is small (see Moraga et al., 2003, Hwang, 2006).

$$
-F_{T D, d}=-\rho_{d} \frac{\beta_{c}}{\beta_{d}}\left(\frac{\beta_{c}}{\beta_{c}+\beta_{d}}\right)\left\langle u_{c}^{\prime} u_{c}^{\prime}\right\rangle \nabla \Phi=-C_{T D} \rho_{d} k_{c} \nabla \Phi
$$

A Favre-Averaged form of the turbulent dispersion force was developed to exploit the convenience using mass-weighted averages to express the ensemble averages of the flow variables (see Gosman 1992, Burns et al. 2004). This convenience is based on fewer variables from the continuity equations that require direct modelling:

$$
-F_{T D, d}=-C_{T D} \frac{3}{4} \frac{C_{D}}{d_{F}} \rho_{C} V_{r e l} \frac{v_{t, c}}{\operatorname{Pr}} \nabla \Phi
$$




\subsection{Modeling of fiber sedimentation and resuspension}

In the characterisation of the solids suspended in wastewater treatment clarifiers, three shear dependent viscosity models are considered as reported by de Clerq (2002). The Newtonian linear model as presented in equation (11), the non-linear model in equation (12) characterised pseudoplastic and dilatant fluid mixtures. Other non-linear models were the third group that represented fluid mixtures with Herschel-Buckley or Bingham plastic properties (equations (13) to (16)).

$$
\tau=\mu \gamma=\mu \frac{\partial u_{c}}{\partial x}
$$

where the shear stress, $\tau$, is equivalent to the product of the viscosity and the velocity gradient, defined as the strain rate, $\gamma$.

$$
\begin{array}{r}
\tau=K \gamma^{n_{K}}\left\{\begin{array}{cc}
n<1 & \text { Pseudoplastic }=\text { Shear }- \text { thinning } \\
n>1 & \text { Dilatant }=\text { Shear - thickening }
\end{array}\right. \\
\tau=\tau_{0}+K \gamma^{n_{K}} \quad\left\{\begin{array}{cc}
\tau \geq \tau_{0} & \gamma \neq 0 \\
\tau<\tau_{0} & \gamma=0 \\
0<n<\infty & \text { Herschel }- \text { Bulkley } \\
n=1 & \text { Bingham - plastic }
\end{array}\right.
\end{array}
$$

where the fluid consistency, $\mathrm{K}$, can represent the viscosity and flow behaviour index, $\mathrm{n}_{\mathrm{K}}$, describes the behaviour of the fluid and $\tau_{0}$ is the yield stress. Slatter (1997) proposed three equations (14) to (16) to determine the dependency of the volume fraction on all three parameters.

$$
\begin{gathered}
\tau_{0}=a_{1} \frac{\Phi^{3}}{\Phi_{m}-\Phi} \\
K=\mu\left(1-\frac{\Phi}{\Phi_{m}}\right)^{-b_{l}}
\end{gathered}
$$




$$
n_{K}=c_{1} \Phi^{2}+c_{2} \Phi+1
$$

In the simulations of a secondary clarifier, the viscosity of the fluid solid-mixture was treated as a plastic solid in the form of a Bingham plastic. However, the form of the equations used differed to the semi empirical model in equations (13) to (16). De Clerq (2002) obtained equations (17) to (19) from measurements performed on wastewater treatment liquors that undergo clarification.

$$
\begin{gathered}
\tau=\frac{\tau_{0}}{\gamma}\left(1-e^{-b_{2}}\right)+K \gamma^{n_{K}-1} \\
\tau_{0}=a_{2} \Phi^{a_{3}} \\
K=\mu+b_{3} \Phi^{2}
\end{gathered}
$$

Therefore, to derive correctly the numerous coefficients for the volume fraction of mineral wool fibres studies of the influence of shear on the mixture viscosity must be performed. A drawback of such models is that at strain rates approaching zero, the viscosity increases to infinity as the fluid begins to behave as a rigid body. This led to a divergence of the computational models in the regions of suspended solids where the velocities are very small. Recently Weiss et al. (2006) have applied two viscosity models for the different flow regimes present in secondary clarifiers that can be distinguished by the amount of shear the fluid mixture experiences. At high shear rates, the Bingham plastic model was applied with empirically derived coefficients, and in order to overcome the instabilities that occurred at low shear rates, an empirically derived Casson model was used (29). Note that $K_{0 c}$ is the square root of the yield stress and $K_{c}$ is the square root of the Casson plastic viscosity.

$$
\tau^{0.5}=K_{0 c}+K_{c}(\gamma)^{0.5}
$$


In the assessment of the variation of viscosity with the dispersed phase fraction of solidliquid mixtures, a number of models based on the product of a relative viscosity and the liquid phase have been developed according to equations (21) to (26). Equation (22) was reported in the development of sedimentation and resuspension models. However, this formulation was not used as the correlation was based on small polystyrene spheres (see Leighton and Acrivos (1987), Miskin et al. (1986)).

$$
\begin{gathered}
\mu_{m}=\mu_{r} \mu_{c} \\
\mu_{r}=\left[1+\frac{1.5 \Phi}{1-\Phi / \Phi_{m}}\right]^{2}
\end{gathered}
$$

Rao (1999) reported several correlations from Kitano et al. (1981), Krieger et al. (1959), Maron et al. (1956), Metzner (1985) and Quemanda et al. (1985) that have been used in assessing the viscosity of solid-liquid mixtures that are prevalent in the preparation of processed foods. The correlations were equations (22) (Krieger et al. 1959), (23) (Kitano et al., 1981, Maron et al., 1956), and (24) (Metzner, 1985). Equations (22) to (24) correlations were based on a modification of Maron-Pierce correlations, equation (15) (see Maron et al. (1956), Quemanda et al. (1985)). Where $[\mu]$ is the intrinsic viscosity, which is 2.5 for spheres, $K_{K}$ and $K_{Q}$ are shape dependent parameters.

$$
\begin{aligned}
& \mu_{r}=\left[1-\frac{\Phi}{\Phi_{m}}\right]^{-[\mu] \phi_{m}} \\
& \mu_{r}=\left[1-\frac{\Phi}{K_{K}}\right]^{-2} \\
& \mu_{r}=\left[1-\frac{1}{2} K_{Q} \Phi\right]^{-2}
\end{aligned}
$$




$$
\mu_{r}=\left[1-\frac{\Phi}{\Phi_{m}}\right]^{-2}
$$

However, these correlations (equations (21) to (26)) were found to be divergent at high volume fractions as the viscosity increased exponentially. This has lead to calculation instabilities close to the base of the channel, where high volume fractions of the particulate phase could accumulate.

A modification (equation 27) of the effective viscosity first found by Einstein was proposed by Batchelor (1977) and reported by Xu et al. (2005). The modification is the result of the addition of the last, second order term to the equation to represent the influence that Brownian motion on the bulk stress, which is of the order of 2 . The coefficient of the second order term, $\mathrm{K}_{\text {hyd }}$, is dependent on the local hydrodynamic conditions, the rheology of the fluid mixture, uniformity of particle probability distribution, and isotropy of the turbulence. Such that the value of the coefficient was determined as 6.2 for uniform distributions in a Newtonian mixture, as 7.6 for non-uniform distributions in a purely straining isotropic flow, and at time of publication a third undetermined value for simple shearing non-isotropic flows (see Batchelor (1977)).

$$
\mu_{r}=1+[\mu] \Phi+K_{h y d} \Phi^{2}
$$

Another empirical model for the viscosity is the correlation

$$
\mu_{r}=1+\left\{\begin{array}{cr}
0 & \Phi<0.6 \\
\Phi^{3} \cdot 10^{4} & \Phi \geq 0.6
\end{array}\right.
$$

An alternative empirical model that could improve the closure of the numerical models by the relative viscosity is that of equation (29), which was derived from the experimental study of the viscosity of fibre suspensions at several concentrations (Milliken et al. (1989); Powell (1991)). However, the value of the intrinsic viscosity is markedly different with a 
value of 27.6, which has a much stronger influence of the relative viscosity at much lower concentrations. Using this value in equations (23) and (27) also gives an increased effect of lower volume fractions on the flow phenomena.

$$
\mu_{r}=1+\left\{\begin{array}{cc}
{[\mu] \Phi^{1.01}} & \Phi<0.125 \\
2040 \Phi^{3.01} & \Phi \geq 0.125
\end{array}\right.
$$

The influence of the formulation of the eddy viscosity, $v_{t}$, varies with the application of the turbulence transport model (equations (31) and (32)). This term has a direct effect on the turbulence dispersion force as defined by equation (10) and the deviatoric stress tensor in the equation of the conservation of momentum via the strain rate tensor and the effective viscosity. The effective viscosity is determined from the sum of the fluid viscosity and the eddy viscosity:

$$
v_{t, c}=c_{\mu} \frac{k_{c}^{2}}{\varepsilon_{c}}
$$

The eddy viscosity has the form of a kinematic viscosity with the unit's $\mathrm{m}^{2} \mathrm{~s}^{-1} \cdot \mathrm{c}_{\mu}, \mathrm{k}_{\mathrm{c}}$ and $\varepsilon_{\mathrm{c}}$ are a constant with a value of 0.09 , the turbulent kinetic energy and the turbulent eddy dissipation rate. Equation 30 is used in the widely used k- $\varepsilon$ turbulence model. However, an alternative turbulence model known as the SST (shear stress turbulence) model was selected. It is a combination of the $\mathrm{k}-\varepsilon$ and $\mathrm{k}-\omega$ turbulence models, which can more accurately model the smaller scales of turbulence in the near wall region. This model consists of several functions that vary according to the distance from the nearest wall $\left(\mathrm{y}_{\mathrm{w}}\right)$ by switching between $\varepsilon_{\mathrm{c}}$ and $\omega_{\mathrm{c}}$ (turbulence frequency) forms of the transport equations for smaller scale turbulence.

$$
v_{t, c}=\frac{c_{\mu}^{0.5} k_{c}}{f_{\max }\left\{c_{\mu}^{0.5} \omega_{c}, \quad 2 \gamma_{i j} \tanh \left(f_{\max }\left\{\frac{2 k_{c}{ }^{0.5}}{c_{\mu} \omega_{c} y_{w}}, \frac{500 v_{c}}{y_{w}{ }^{2} \omega_{c}}\right\}^{2}\right)\right\}}
$$


Where $\omega_{\mathrm{c}}=\varepsilon_{\mathrm{c}} /\left(\mathrm{c}_{\mu} \mathrm{k}_{\mathrm{c}}\right)$ and $\gamma_{\mathrm{ij}}$ is the strain rate tensor, which is defined as equation (32) and it is used to determine the shear strain rate and the deviatoric stress tensor. Note that the turbulence of the dispersed phase is resolved by assuming that the dispersed phase eddy viscosity is equivalent to $v_{\mathrm{t}, \mathrm{c}} / \mathrm{Pr}$.

$$
\gamma_{i j}=\frac{1}{2}\left(\frac{\partial U_{i}}{\partial x_{j}}+\frac{\partial U_{j}}{\partial x_{i}}\right)
$$

\section{VALIDATION OF THE MODELS BY MEANS OF EXPERIMENTS}

\subsection{Determination of the drag coefficient in the test rig "column"}

To determine the drag coefficient of the particles, the motion of settling particles were studied in the test rig "column". The particles were obtained from steam-blasting experiments and they are inserted into a Plexiglas column. The column has a height of $3 \mathrm{~m}$, a width of $0.5 \mathrm{~m}$ and a depth of $0.1 \mathrm{~m}$. A numerical evaluation of the distribution of sinking velocities was determined using high-speed video (Fig. 1). At the IPM-Zittau, different methods of the Fuzzy Logic were applied to establish a classification of the particles. Furthermore, an application of Takagi-Sugeno fuzzy models was employed to calculate the terminal sinking velocities of single particles by using size and several shape-describing indicators as input parameters.

\section{Figure 1}

From the numerical analysis, a distribution of sinking velocities was found (on the right side of Fig. 1). The particles consist of an agglomeration of smaller particles of different sizes, densities and shape. Larger objects are disintegrated under the influence of the shear stresses and turbulence from the surrounding liquid. The turbulent wake of the larger particle agglomerations causes breakage of the following agglomerations that result in the generation of finer particle fractions. 
Extensive tests have shown that the sinking behaviour not only depends on the insulation material itself, but also on the wettability of the fibres, which is influenced by the age, the kind of drying and the hydrophobic properties and finally on the preparation procedure of the material.

\section{Figure 2}

Fig. 2 shows the sinking velocities of different insulation fibre materials. The values for the MD-2 type were measured at the facility in Zittau. Furthermore comparable velocities of other materials published in the NUREG/CR-6808 are shown. The dependency of the sinking velocity on the fragmentation procedure is also depicted in Fig. 2 for MD-2 fibres. The fragmentation by a steam jet that was performed in the facility in Zittau results in sinking velocities of $0.005-0.12 \mathrm{~m} / \mathrm{s}$ while the manual fragmentation results in larger particles and larger sinking velocities of $0.01-0.2 \mathrm{~m} / \mathrm{s}$.

\section{Figure 3}

Due to the many influences that affect the sinking velocity, the Schiller-Naumann correlation according to equation (5) was applied. Then the sinking velocity was calculated iteratively according to equation (7). Fig. 3 shows the sinking velocity for different combinations of virtual particle diameter and virtual particle density. The investigated material shown in Fig. 1 (right side) has an average sinking velocity of $0.03 \mathrm{~ms}^{-1}$, which is found for a virtual density of $1015 \mathrm{~kg} \mathrm{~m}^{-3}$ and a virtual particle diameter of $5 \mathrm{~mm}$. The assumed virtual particle size corresponds to typical values of observations. For these parameters for the sinking test a Re number of ca. 150 and a drag coefficient of ca. 0.9 can be calculated. The density of dry fibres was $2800 \mathrm{~kg} \mathrm{~m}^{-3}$ that gives the dry fibre share in the virtual particle of 0.0067 . 
The adjustment of the virtual particle density and virtual particle size to reproduce the measured sinking velocity ensures that the simulation is correct for this flow situation. The application of the correct drag force correlation is therefore only questionable for relative velocities, which may differ significantly from the sinking velocity. However, for more complex flow situations that are described later, the relative velocity between water and virtual particles has been found to be similar to the terminal sinking velocity over almost the entire flow region considered.

The phenomena observed in the column were simulated by CFX. The transient started when a known mass of fibres was placed in the upper part of the column. The mass flow through virtual horizontal planes at several height positions was calculated and compared to measurements. To compare the calculated results with the measured area fractions of the vertical observation planes occupied by the particles that were obtained from video observations. Motion in the extension across the depth of the column was neglected. The maximum calculated mass flow rate corresponds to the observation, since the average sinking velocity of $0.1 \mathrm{~m} \mathrm{~s}^{-1}$ was adjusted to this value by using a simulated particle diameter of $5 \mathrm{~mm}$ and a particle density of $1080 \mathrm{~kg} \mathrm{~m}^{-3}$. The observed width of the maximum is caused by the scattering of sinking velocities and by the interaction with the liquid flow field in the column. Good agreement between the simulations at the assumed width and the experimental observations was observed for the peak fraction; however, this changed as the effect of wake induced turbulence on particle motion and breakage reduced the sink rate resulting in the differences in the mass flow rates in the 40 seconds following the start of the test (see Fig. 4).

\section{Figure 4}

The demonstration given in this chapter shows that the Eulerian-Eulerian approach applied here is limited to the description of a certain particle size and density, whereas in the experiments, a particle spectrum is observed (see Fig. 1, right side). In principle, the Eulerian- 
Eulerian approach enables the simulation of different dispersed phases representing different particle sizes and densities. Furthermore, in the Eulerian-Lagrangian approach from its fundamental principle, the definition of a spectrum of particle sizes and densities is possible. All these measures increase the numerical effort and reduce the numeric stability, which can limit the applicability of the models for the solution of practical problems. The required accuracy of the practical question to be answered has to decide on the preferred method.

\subsection{Simulation of the water flow in the test facility "channel"}

The transport properties of fibres in a turbulent water flow is investigated experimentally in a flat race track type channel with a width of $0.1 \mathrm{~m}$, a depth of $1.2 \mathrm{~m}$ and straight sections with a length of $5 \mathrm{~m}$ (see Fig. 5). The bends have a radius of $0.5 \mathrm{~m}$. The water flow is driven by two slow moving pumps driving the liquid at velocities between 0.01 and $1.0 \mathrm{~m} \mathrm{~s}^{-1}$. The fibre distribution and the water velocity field were observed by using highspeed video and by Laser based PIV.

\section{Figure 5}

The channel was designed to obtain exactly defined flow boundary conditions. During preliminary investigations the flow conditions were investigated for water flow. The pumps were simulated as momentum sources. A source of $26 \mathrm{~N}$ for each pump yielded a circular velocity of about $0.5 \mathrm{~m} \mathrm{~s}^{-1}$. It could be shown that particularly the channel curves had a smoothing effect on the vertical flow profile. Therefore, the pumps feed into the first curve and the tests are performed in a channel section behind the pumps (see Fig. 6).

\section{Figure 6}

\section{Figure 7}

To provoke a flow disturbance the channel was equipped with 0.1 and $0.2 \mathrm{~m}$ high baffles separated by a distance of $0.3 \mathrm{~m}$ (see Fig. 6). The flow field was calculated and 
measured by PIV laser techniques. Fig. 7 shows the flow field near the baffle plates. The measurements and calculations were compared at vertical profiles at $0.017 \mathrm{~m}$ before the first plate (line 1) and central between the plates (line 2), (see Fig. 7 right side). The excellent agreement of the measured and calculated profiles for the pure water flow serves as essential starting point for the further investigations of fibre laden flow.

\subsection{Investigation of the fibre transport in a turbulent water flow}

The observations of the experiments with fibre flow in the circulating water showed that at higher circulation velocities (ca. $>0.5 \mathrm{~m} / \mathrm{s}$ ) the fibre sinking is replaced by a horizontal transport of the fibres. This phenomenon can be simulated considering the turbulence dispersion force (see chapter 3.3).

Fig. 8 shows the fibre distribution in the channel without considering the turbulent dispersion force. Almost the whole particle phase is deposited at the bottom. For a virtual particle density of $1030\left[\mathrm{~kg} \mathrm{~m}^{-3}\right]$ which results in a sinking velocity of $0.05\left[\mathrm{~m} \mathrm{~s}^{-1}\right]$ the buoyancy force $F_{B}$ (see eq. 6) is estimated to be between 10 and $100\left[\mathrm{~kg} \mathrm{~m}^{-2} \mathrm{~s}^{-2}\right]$. CFD simulations of the channel for the case of an averaged water velocity of ca. $0.5\left[\mathrm{~m} \mathrm{~s}^{-1}\right]$ resulted in an averaged turbulence viscosity in the order of $0.25\left[\mathrm{~kg} \mathrm{~m}^{-1} \mathrm{~s}^{-1}\right]$. Keeping in mind that the drag coefficient for the virtual particle flow in water of ca. 0.8 and assuming reasonable values for the volume fraction gradient of ca. $0.1\left[\mathrm{~m}^{-1}\right]$ the turbulent dispersion force (see eq. (10) becomes comparable to the buoyancy force $F_{B}$ with a coefficient $C_{T D}$ in the order of ca. 100. Indeed, Fig. 9 shows that the simulation considering the turbulent dispersion force here with $C_{T D}$ of 250 has a smoother vertical distribution of the fibres in the channel. The dependency of the vertical profile of the fibre volume fraction on the value of the turbulent dispersion force was shown. Fig. 10 presents the vertical profiles for different values of the coefficient $C_{T D}$. Experiments measuring the vertical profile of the fibre volume fraction for different water velocities are in preparation. 


\section{Figure 8}

\section{Figure 9}

\section{Figure 10}

\subsection{Investigation of the sedimentation and re-suspension behaviour of the fibres}

For the investigation of the sedimentation and re-suspension properties of fibres, the region between the baffles was particularly observed. The obstacles in the straight sections not only disturb the motion of the liquid, but also promote deposition of the particles.

The experiments revealed that the fibres agglomerate at a critical fibre volume fraction, which is manifested by a strong increase of viscosity. In addition, the fibres are deposited at the bottom of the channel below a critical water velocity of about $0.1 \mathrm{~m} / \mathrm{s}$, particularly at locations downstream of the obstacles. Increasing the water velocity beyond $0.1 \mathrm{~m} / \mathrm{s}$ causes the fibres to be mobilized again.

The application of the Eulerian-Eulerian approach for the sedimentation and resuspension of the fibres involved the use of volume fraction dependent viscosities (see chapter 3.4) and the turbulent dispersion force (chapter 3.3). The original concept for the proposed simulations considered the fluid mixture as a Non-Newtonian fluid, which is based on the simulation of a shear stress dependent viscosity. However, observations of the fibrous flow in the channel have shown that there is a volume fraction dependent behaviour of the fibres. Therefore, during this step a dependency on the virtual particle volume fraction was simulated.

A feasibility study of the accumulation of fibres between two dams arranged at a distance of $0.3 \mathrm{~m}$ and having a height of $0.1 \mathrm{~m}$ was calculated by a transient CFX calculation and investigated in the experiment (see Fig. 11 and 12).

\section{Figure 11}


The mass of fibres accumulated between the dams in the experiments and simulations are presented in Fig. 11 and 12. The effect of the particle phase viscosity was investigated by many CFD calculations applying several of the correlations given in chapter 3.4. Fig. 12 shows as an example the effect of the viscosity dependency according to equation (27). The results show that the CFD code at least is able to simulate the qualitative behaviour of the fibrous flow. Further investigations are underway to provide a deeper analysis of these experiments. The evaluation of area fractions of the vertical observation plane occupied by the particles, which are gained from video observations of the fibrous volume fraction, can be interpreted as a measure for the accumulated fibre mass. Neglecting the extension in the channel depth, these measurements will yield the necessary information in order to improve the physical representation of the solid phase with regards to the solid build-up observed in the experiments.

\section{Figure 12}

\section{SIMULATION OF STRAINERS}

Filter cakes composed of fibrous materials have two particular features: (1) They are of very high porosity, and (2), due to the deformability of the fibres, such cakes can be easily compressed under the action of fluid drag forces or an external compacting pressure. A semiempirical model has been developed for calculating the pressure drop across beds of this class of materials as a function of superficial velocity and material properties (Grahn et al. 2006). It consists of a material equation

$$
\varepsilon(p)=\varepsilon_{\min }+\left(\varepsilon_{0}-\varepsilon_{\min }\right) e^{-C p^{D}}
$$

which describes the dependency of porosity on the compaction pressure $\mathrm{p}_{\mathrm{k}}$, and a differential equation for the local pressure drop: 


$$
\frac{d p_{k}}{d x}=-\frac{d(\Delta p)}{d x}=a\left(A_{S} \rho_{d}\right)^{2}(1-\varepsilon)^{1.5}\left[1+a_{0}(1-\varepsilon)^{3}\right] \mu_{c} U+b \frac{A_{S} \rho_{d}(1-\varepsilon)}{\varepsilon^{3}} \rho_{c} U^{2}
$$

It is a combination of Davis and Ergun equations for the linear and quadratic contributions to the overall pressure drop (Zigler et al., 1995).

An algorithm has been implemented, which solves the model equations by numerical integration. It yields pressure and porosity profiles along the compressed fibre bed as well as its streamwise thickness and the overall pressure drop, $\Delta p$. Parameters $\varepsilon_{m i n}, \varepsilon_{0}, C$ and $D$ of the material equation have been fitted to data from compaction pressure vs. porosity measurements. In the present state of the model, the transient pressure build-up can be simulated as well by specifying a non-zero mass fraction of insulation material for the inflow. The model was also implemented into the CFD code ANSYS CFX to enable the simulation of partially clogged strainers.

The pressure drop across the compressed fibre bed has been determined both numerically and experimentally as a function of superficial velocity. Moreover, experimental conditions, i.e. strainer mass load and fluid properties have been varied (Table 1). For comparison, computed curves and measured values are plotted into one diagram, Fig. 13. It can be seen, that numerical calculations reproduce measured pressure drops qualitatively and quantitatively well.

\section{Table 1}

\section{Figure 13}

Another phenomenon, which has been investigated, is the so-called thin-bed effect. It results from relatively small (as compared to fibre dimensions) granular particles that are deposited, either onto the outer (upstream) surface of the fibre bed or in between the fibres. They form layers of sludge with lower porosity and much lower compressibility, but result in 
a higher pressure-drop with the addition of each layer. Such layers act like a plug, imposing an additional external compacting pressure onto the fibre bed. Transient calculations have been performed to assess the influence of the penetration depth of particles on the overall pressure drop. The penetration depth depends on the nature and the magnitude of particlefibre interaction. From comparison of the different cases in Fig. 14 one can conclude, that the additional modelling effort for quantifying the particle-fibre interaction is not justified.

\section{Figure 14}

\section{PLUNGING JET AND THE VELOCITY FIELD IN A WATER TRAP}

According to the considered scenario, the water ejected by the anticipated break falls several meters on to the sump water surface. On its way, the jet is mixed with air. Furthermore, the impinging jet will entrain air bubbles. The momentum impact of the jet on the water flow field will be smeared out with growing penetration depth. The entrained gaseous bubbles will rise and have an additional influence the flow field. The jet-induced flow in the sump will sensitively influence the fibre transport in the sump. The questions in this concern are how the fibre transport in the sump is influenced by the jet and where in the sump the fibres preferably are deposited.

To investigate the influence of a plunging jet experiments in a water tank with dimensions of about $1 * 1 * 1 \mathrm{~m}$ are prepared. The fluid flow field is measured by laser PIV measurements. The gas flow is observed by high-speed video. CFD calculations are performed to prepare the experiments.

During the presented CFD calculations, the phenomenon of the air entrainment by the jet is excluded but given as an inlet condition. Therefore, published correlations for the air entrainment are applied, as the aim of the calculations is the determination of the flow field in the volume. 
Correlations on gas entrainment at a plunging jet were published by Bin (1993), Bonetto et al. (1993), Cummings et al. (1997a and b) and Iguchi et al. (1998). Bin (1993) reports the following empirical correlation. A water volume flow $Q_{W}$ hit from a height $H$ with the diameter $d_{i}$ and the velocity $U_{O F}$ at a water surface entrains the volume flow $Q_{G}$ of gaseous bubbles:

$$
Q_{G}=0,04 Q_{W} F^{0.28}\left(\frac{H}{d_{i}}\right)^{0,4}
$$

Fr is the Froude Number:

$$
F r=\frac{U_{O F}^{2}}{g d_{i}}
$$

The maximum penetration depth $Z_{P, B}$ of bubbles is given by

$$
Z_{P, B}=0,42 U_{O F}^{4 / 3} d_{i} Q_{G}^{-1 / 4}
$$

Assuming a jet inlet velocity of $3 \mathrm{~m} / \mathrm{s}$ and an impingement diameter on the surface of $0.05 \mathrm{~m}$ according to eq. (35) an air entrainment having a volume flow $Q_{G}$ of ca. $0.2 * Q_{W}$ has to be expected. The corresponding maximum gas penetration depth was calculated by eq. (37) to be ca. $0.5 \mathrm{~m}$.

Fig. 15 shows the results of CFD calculations. At the inlet, a water flow of $3 \mathrm{~m} / \mathrm{s}$ having a gas content of 0.2 is simulated. The water is drained out of the tank via the outlet at the bottom. The entrained gas leaves the tank via the water surface. Fig 15 shows the gas streamlines calculated according to the gas velocity field. The maximum gas penetration depth is determined by the lowest point of the zero value of the vertical component of the gas velocity field. The value of ca. $0.5 \mathrm{~m}$ predicted by eq. (37) is confirmed by the CFD calculations. 
Fig. 16 shows the influence of the gas entrainment on the liquid velocity field near the jet. The entrained bubbles near the jet will rise and decrease the water velocity. The profiles $0.2 \mathrm{~m}$ below the water surface shown in Fig. 16 indicate an upward water flow near the jet. The streamlines of the water flow projected on a middle plane in the tank show for the single phase case two vertices near the tank bottom. In the two-phase case, these vertices are shifted towards the upper regions (see Fig. 17).

The planned experiments are used to tune these bubble entrainment correlations and fit them to the expected boundary conditions. The gained experience can then be applied to questions of real sump geometries.

\section{SUMMARY AND NEXT STEPS}

The project work is still underway. Several model concepts were presented to describe the whole process of fibre transport applying CFD methods. The presented results show, that the intended model approaches are feasible for the simulation of the phenomena of interest. The paper shows the correct qualitative behaviour of the solutions and the correct dependency of model parameters. The aim of the work was the preparation of the necessary experiments to adjust the free parameters.

The developed models including the adjusted model parameters will enable the resolution of many practical questions relating to the strainer clogging issue.

\section{Acknowledgements}

The reported investigations are funded by the German Federal Ministry of Economy and Labour under contract No. 1501270 and 1501307. 


\section{REFERENCES}

Knowledge Base for Emergency Core Cooling System Recirculation Reliability, NEA/CSNI/R(95)11

Knowledge Base for the Effect of Debris on Pressurized Water Reactor Emergency Core Cooling Sump Performance, NUREG/CR-6808; LA-UR-03-0880

Knowledge Base for Strainer Clogging -- Modifications Performed in Different Countries Since 1992, NEA/CSNI/R(2002)6

Debris impact on Emergency coolant recirculation, Workshop Albuquerque, NM, USA February 2004, Proceedings OECD 2004 NEA No. 5468

Batchelor, G.K., The effect of Brownian motion on the bulk stress in a suspension of spherical particles, Journal of Fluid Mechanics 83, (1977), 97-117.

Bin, A. K. (1993): Gas entrainment by plunging liquid jets, Chem. Eng. Sci. Vol. 48, pp. $3585-3630$

Bonetto, F., Lahey Jr., R.T. (1993): An experimental study on air carry under due to a plunging liquid jet, Int. J. Multiphase Flow Vol. 19, No. 2, pp. 281-294

Burns, A. D., T. Frank, I. Hamill J.-M. Shi, The Favre Averaged Drag Model for Turbulent Dispersion in Eulerian Multi-Phase Flows, 5th International Conference on Multiphase Flow, ICMF’04, Yokohama, Japan, May 30-June 4, 2004, Paper No. 392.

Carrica, P.M., D. Drew, F. Bonetto, R.T. Lahey Jr, A polydisperse model for bubbly twophase flow around a surface ship, International Journal of Multiphase Flow 25, (1999), 257-305.

Cummings, P.D., Chanson, H. (1997a): Air entrainment in the developing flow region of plunging jets - Part1: Theoretical Development, Transactions of the ASME, Journal of Fluids Engineering Vol. 119, pp. 597-602

Cummings, P.D., Chanson, H. (1997b): Air entrainment in the developing flow region of plunging jets - Part2: Experimental, Transactions of the ASME, Journal of Fluids Engineering Vol. 119, pp. 603-608

De Clerq, B., Computational fluid dynamics of settling tanks: development of experiments and rheological, settling, and scraper submodels, $\mathrm{PhD}$ Thesis, Universiteit Gent, Belgium, 2002

Frank, Th.: Parallele Algorithmen für die numerische Simulation dreidimensionaler, disperser Mehrphasenströmungen und deren Anwendung in der Verfahrenstechnik, Shaker Verlag Aachen 2002

Grahn, A.; Krepper, E.; Alt, S.; Kästner, W.: Modelling of differential pressure buildup during flow through beds of fibrous materials, Chemical Engineering and Technology 29 (2006), 997 - 1000

Haider, A., Levenspiel, O.: Drag coefficient and terminal velocity of spherical and non spherical particles, Powder Technology Vol. 58, (1989), pp. 63-70

Hwang, W.; Eaton, J.K.: Turbulence attenuation by small particles in the absence of gravity, International Journal of Multiphase Flow 32, (2006), 1386-1396 
Iguchi, M., Okita, K., Yamamoto, F. (1998): Mean velocity and turbulence characteristics of water flow in the bubble dispersion region induced by plunging water jet, Int. J. Multiphase Flow Vol. 24, No. 4, pp. 523-537

Kitano, T., T. Kataoka, T. Shirota, An empirical equation of the relative viscosity of polymer melts filled with various inorganic fillers, Rheologica Acta 20, (1981), 207-209.

Krieger, L.M., T.J. Dougherty, A mechanism for non-Newtonian flow in suspensions of rigid spheres, Transactions of the Society of Rheology 3, (1959), 137-152.

Leighton, D., A. Acrivos, Viscous Resuspension, Chemical Engineering Science 44(6), (1986), 1377-1384.

Lopez de Bertodano, M.A., Two fluid model for two-phase turbulent jets, Nuclear Engineering and Design 179, (1998), 65-74.

Maron, S.H., P. E. Pierce, Application of Ree-Eyring generalized flow theory to suspensions of spherical particles, Journal of Colloid Science 11, (1956), 80-95.

Metzner, A.B., Rheology of suspensions in polymeric liquids, Journal of Rheology 29, (1985), 739-775.

Milliken, W. J., Gottlieb, M., Graham, A. L., Mondy, L. A., \& Powell, R. L. The viscosityvolume fraction relation for suspensions of rod-like particles by falling-ball rheometry, Journal of Fluid Mechanics 202, (1989), 217 - 232

Miskin, I., L. Elliott, D. B. Ingham, P. S. Hammond, The viscous resuspension of particles in an inclined rectangular fracture, International Journal of Multiphase Flow 22(2), (1996), 403-415.

Moraga, F.J., F.J. Bonetto, R.T. Lahey, Lateral forces on spheres in turbulent uniform shear flow, International Journal of Multiphase Flow 25, (1999), 1321-1372.

Moraga, F.J., A.E. Larreteguy, D.A. Drew, R.T. Lahey Jr, Assessment of turbulent dispersion models for bubbly flows in the low Stokes number limit, International Journal of Multiphase Flow 29, (2003), 655-673.

Powell, R. L. Rheology of suspensions of rod like particles, Journal of Statisical Physics, 62, (1991), $1073-1094$

Quemada, D., P. Fland, P.H. Jezequel, Rheological properties and flow of concentrated disperse media, Chemical Engineering Communications 32, (1985), 61-83.

Rao, M.A., Rheology of fluid and semisolid foods: Principles and Applications, SpringerVerlag USA, 1999.

Reeks, M.W., On a kinetic equation for the transport of particles in turbulent flows, Physics of Fluids A - Fluid Dynamics 3(3), (1991), 446-456.

Salman, A.D., Verba, A.: New approximate equations to estimate the drag coefficient of different particles of regular shape, Periodica Polytechnica of the Technical University Budapest - Chemical Engineering, Vol. 32 (1988), No. 4, pp. 261-268

Schiller, L. and Nauman, A., (1933). VDI Zeitschrift, vol. 77 p 318.

Shi, J.M., T. Frank, E. Krepper, D. Lucas, U. Rohde, H.-M. Prasser, Implementation and validation of non-drag interfacial forces in CFX 5.6, 5th International Conference on Multiphase Flow, ICMF’04, Yokohama, Japan, May 30-June 4, 2004, Paper No. 400. 
Slatter, P. T., The rheological characterisation of sludges, Water Science and Technology 36(11), (1997), 9-18

Turney, M. A., Cheung, M. K., Powell, R. L., McCarthy, M. J.: Hindered Settling of RodLike Particles Measured with Magnetic Resonance Imaging, AIChE Journal, Vol. 41, No. 2 (1995)

Weiss, M., Plosz, B., K. Essemiani, J. Meinhold, Sedimentation of Activated Sludge in Secondary Clarifiers, In: Proceedings of the 2006 Spring National Meeting of the AICHE, Orlando, Florida (abstract_35269.htm).

Xu, J., S. Chatterjee, K.W. Koelling, Y. Wang, S. E. Bechtel, Shear and extensional rheology of nanocarbon fiber suspensions, Rheologica Acta 44, (2005), 537-562 


\section{Nomenclature}

\begin{tabular}{|c|c|c|}
\hline Sign & Unit & Denomination \\
\hline A & $\mathrm{m}^{2}$ & contact area \\
\hline$A_{s}$ & $\mathrm{~m}^{2} \mathrm{~kg}^{-1}$ & specific surface area of a fibre \\
\hline $\mathrm{a}, \mathrm{a}_{0}$ & - & $\begin{array}{l}\text { experimentally determined coefficients used to } \\
\text { determine the local pressure drop }\end{array}$ \\
\hline$a_{1}, a_{2}, a_{3}$ & - & $\begin{array}{l}\text { experimental factors for volume fraction dependency } \\
\text { of the yield stress }\end{array}$ \\
\hline b & & $\begin{array}{l}\text { experimentally determined coefficient used to } \\
\text { determine the local pressure drop }\end{array}$ \\
\hline$b_{1}, b_{2}, b_{3}$ & - & $\begin{array}{l}\text { experimental factors for volume fraction dependency } \\
\text { of the fluid consistency }\end{array}$ \\
\hline C & $\left(\mathrm{kg} \mathrm{m}^{-1} \mathrm{~s}^{-2}\right)^{-\mathrm{D}}$ & $\begin{array}{l}\text { experimental determined coefficient for the fibre } \\
\text { compaction pressure porosity dependency }\end{array}$ \\
\hline$C_{D}$ & - & drag coefficient \\
\hline $\mathrm{C}_{\mathrm{TD}}$ & - & turbulence dispersion coefficient \\
\hline$c_{1}, c_{2}$ & & $\begin{array}{l}\text { experimental factors for volume fraction dependency } \\
\text { of the flow behaviour index }\end{array}$ \\
\hline $\mathrm{C}_{\mu}$ & - & turbulence model constant $(0.09)$ \\
\hline $\mathrm{D}$ & - & $\begin{array}{l}\text { experimentally determined index for the fibre } \\
\text { compaction pressure porosity dependency }\end{array}$ \\
\hline$d_{d}$ & $\mathrm{~m}$ & particle diameter \\
\hline$d_{F}$ & $\mathrm{~m}$ & virtual diameter \\
\hline$d_{i}$ & $\mathrm{~m}$ & impingement diameter \\
\hline$\Delta$ & - & difference \\
\hline $\mathrm{F}_{\mathrm{B}}$ & $\mathrm{kg} \mathrm{m}^{-2} \mathrm{~s}^{-2}$ & buoyancy force \\
\hline $\mathrm{F}_{\mathrm{D}}$ & $\mathrm{kg} \mathrm{m}^{-2} \mathrm{~s}^{-2}$ & drag force \\
\hline $\mathrm{F}_{\mathrm{TD}, \mathrm{d}}$ & $\mathrm{kg} \mathrm{m}^{-2} \mathrm{~s}^{-2}$ & $\begin{array}{l}\text { turbulent dispersion force acting on the dispersed } \\
\text { phase }\end{array}$ \\
\hline $\mathrm{Fr}$ & - & Froude number \\
\hline$f_{\max }$ & & function returning the maximum value of two terms \\
\hline g & $\mathrm{m} \mathrm{s}^{-2}$ & acceleration due to gravity \\
\hline $\mathrm{H}$ & $\mathrm{m}$ & height of jet \\
\hline $\mathrm{h}_{0}$ & $\mathrm{~m}$ & liquid surface height \\
\hline $\mathrm{i}, \mathrm{j}, \mathrm{k}$ & - & numeric indexes \\
\hline K & - & fluid consistency \\
\hline $\mathrm{K}_{0 \mathrm{C}}$ & - & $\begin{array}{l}\text { Casson model yield coefficient (square root of yield } \\
\text { stress) }\end{array}$ \\
\hline $\mathrm{K}_{\mathrm{C}}$ & - & square root of the Casson plastic viscosity \\
\hline $\mathrm{K}_{\mathrm{K}}, \mathrm{K}_{\mathrm{Q}}$ & - & shape dependent relative viscosity parameters \\
\hline $\mathrm{K}_{\text {hyd }}$ & - & flow dependent coefficient \\
\hline $\mathrm{k}_{\mathrm{c}}$ & $m^{2} s^{-2}$ & continuous phase turbulent kinetic energy \\
\hline
\end{tabular}




\begin{tabular}{|c|c|c|}
\hline $\mathrm{L}$ & $\mathrm{m}$ & length \\
\hline $\mathrm{N}_{\mathrm{s}}$ & $\mathrm{kg} \mathrm{m}^{-2}$ & fibre mass loading \\
\hline $\mathrm{n}$ & - & particle number density \\
\hline$n_{K}$ & - & flow behaviour index \\
\hline $\operatorname{Pr}$ & - & turbulent Prandlt number (0.9) \\
\hline $\mathrm{p}$ & $\mathrm{kg} \mathrm{m}^{-1} \mathrm{~s}^{-2}$ & fluid pressure \\
\hline$p_{k}$ & $\mathrm{~kg} \mathrm{~m}^{-1} \mathrm{~s}^{-2}$ & compaction pressure \\
\hline$Q_{G}$ & $\mathrm{~m}^{3} \mathrm{~s}^{-1}$ & volumetric flow of entrained gas bubbles \\
\hline $\mathrm{Q}_{\mathrm{W}}$ & $\mathrm{m}^{3} \mathrm{~s}^{-1}$ & volumetric flow of water jet or stream \\
\hline $\mathrm{Re}$ & - & particle Reynolds number \\
\hline $\mathrm{T}$ & ${ }^{\circ} \mathrm{C}$ & temperature \\
\hline $\mathrm{t}$ & $\mathrm{s}$ & time \\
\hline $\mathrm{U}$ & $\mathrm{m} \mathrm{s}^{-1}$ & superficial continuous phase velocity \\
\hline$U_{i}$ & $\mathrm{~m} \mathrm{~s}^{-1}$ & continuous phase velocity tensor \\
\hline $\mathrm{U}_{\mathrm{OF}}$ & $\mathrm{m} \mathrm{s}^{-1}$ & velocity at the water surface \\
\hline $\mathrm{V}_{\text {rel }}$ & $\mathrm{m} \mathrm{s}^{-1}$ & relative velocity vector \\
\hline$V_{F}$ & $\mathrm{~m}^{3}$ & virtual particle volume \\
\hline $\mathrm{V}_{\mathrm{S}}$ & $\mathrm{m} \mathrm{s}^{-1}$ & particle terminal or sinking velocity \\
\hline$u_{c}^{\prime}$ & $\mathrm{m} \mathrm{s}^{-1}$ & continuous phase fluctuating velocity \\
\hline$u, v, w$ & $\mathrm{~m} \mathrm{~s}^{-1}$ & velocity components \\
\hline $\mathrm{x}, \mathrm{y}$ & $\mathrm{m}$ & co-ordinates \\
\hline$y_{w}$ & $\mathrm{~m}$ & distance to nearest wall condition \\
\hline$Z_{P, B}$ & $\mathrm{~m}$ & penetration depth of the gas bubbles \\
\hline z & $\mathrm{m}$ & co-ordinates \\
\hline$\alpha_{F}$ & - & share of fibres in virtual particle \\
\hline$\beta_{c}$ & $\mathrm{~s}$ & Lagrangian turbulence time-scale \\
\hline$\beta_{d}$ & $\mathrm{~s}$ & particle relaxation time \\
\hline Y & $s^{-1}$ & strain rate \\
\hline$Y_{i j}$ & $\mathrm{~s}^{-1}$ & strain rate tensor \\
\hline$\varepsilon$ & - & porosity \\
\hline$\varepsilon_{c}$ & $\mathrm{~m}^{2} \mathrm{~s}^{-3}$ & continuous phase turbulent eddy dissipation rate \\
\hline$\varepsilon_{\min }$ & - & minimum porosity \\
\hline$\mu$ & $\mathrm{kg} \mathrm{m}^{-1} \mathrm{~s}^{-1}$ & dynamic liquid viscosity \\
\hline$\mu_{\mathrm{c}}$ & $\mathrm{kg} \mathrm{m}^{-1} \mathrm{~s}^{-1}$ & dynamic continuous phase viscosity \\
\hline$\mu_{\mathrm{m}}$ & $\mathrm{kg} \mathrm{m}^{-1} \mathrm{~s}^{-1}$ & dynamic mixture viscosity \\
\hline$\mu_{\mathrm{r}}$ & $\mathrm{kg} \mathrm{m}^{-1} \mathrm{~s}^{-1}$ & dynamic relative viscosity \\
\hline$[\mu]$ & & intrinsic viscosity \\
\hline $\mathrm{v}_{\mathrm{c}}$ & $\mathrm{m}^{2} \mathrm{~s}^{-1}$ & kinematic viscosity of the continuous phase \\
\hline $\mathrm{v}_{\mathrm{t}, \mathrm{c}}$ & $\mathrm{m}^{2} \mathrm{~s}^{-1}$ & $\begin{array}{l}\text { kinematic turbulent eddy viscosity of the continuous } \\
\text { phase }\end{array}$ \\
\hline
\end{tabular}




\begin{tabular}{|l|l|l|}
\hline$v_{t, d}$ & $\mathrm{~m}^{2} \mathrm{~s}^{-1}$ & $\begin{array}{l}\text { kinematic turbulent eddy viscosity of the dispersed } \\
\text { phase }\end{array}$ \\
\hline$\rho_{\mathrm{c}}$ & $\mathrm{kg} \mathrm{m}^{-3}$ & continuous phase density \\
\hline$\rho_{\mathrm{d}}$ & $\mathrm{kg} \mathrm{m}^{-3}$ & dispersed phase density \\
\hline$\rho_{\mathrm{F}}$ & $\mathrm{kg} \mathrm{m}^{-3}$ & virtual particle density \\
\hline$T$ & $\mathrm{~kg} \mathrm{~m}^{-1} \mathrm{~s}^{-2}$ & shear stress \\
\hline$T_{0}$ & $\mathrm{~kg} \mathrm{~m}^{-1} \mathrm{~s}^{-2}$ & yield stress \\
\hline$\Phi$ & $(-)$ & volume fraction \\
\hline$\Phi_{\mathrm{m}}$ & $(-)$ & maximum volume fraction \\
\hline$\omega_{c}$ & $\left(\mathrm{~s}^{-1}\right)$ & continuous phase turbulent eddy frequency \\
\hline
\end{tabular}




\section{FIGURES}
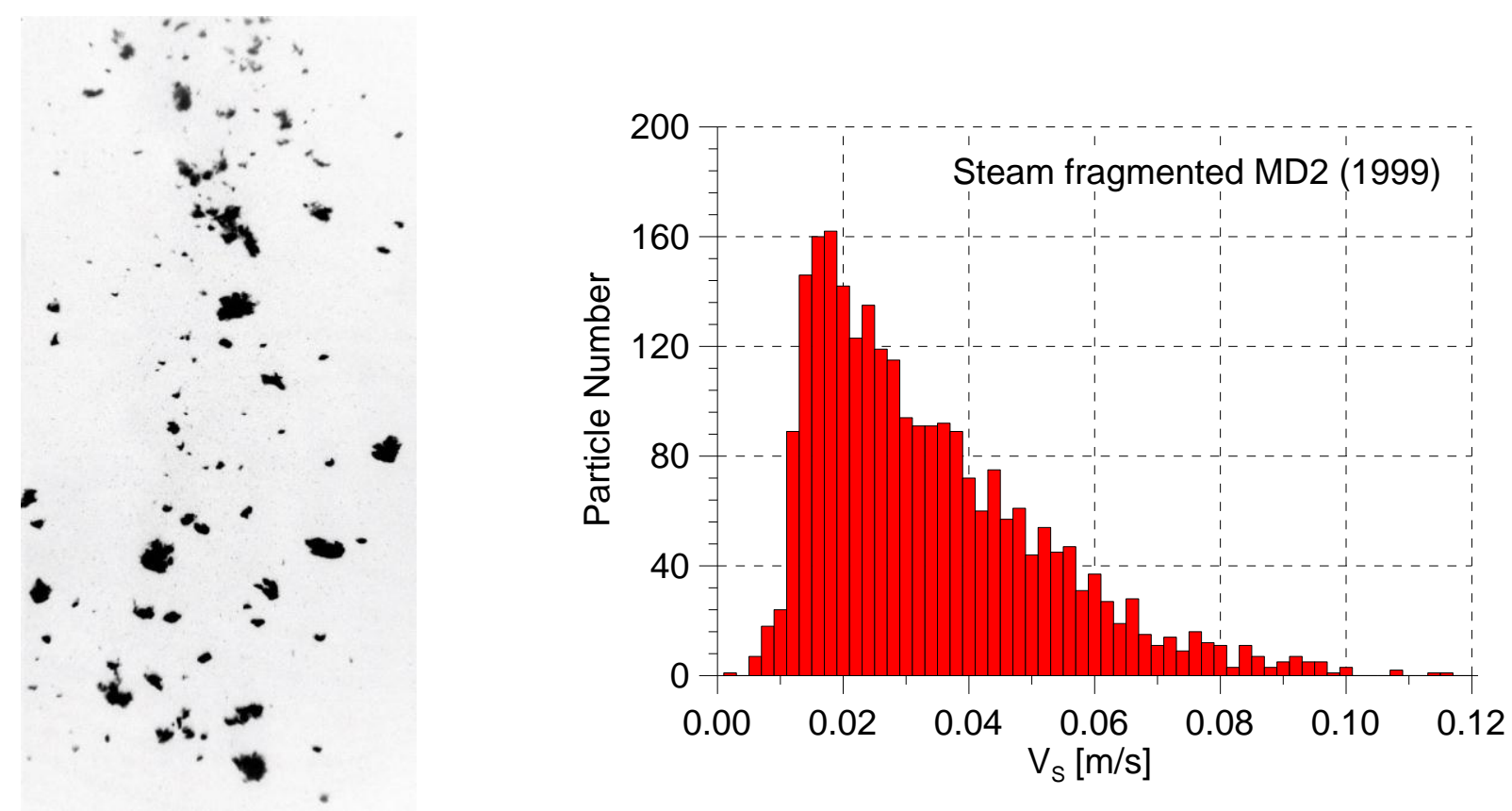

Fig. 1: Photography of sinking fibres (left side) and assessed distribution of sinking velocities measured in the test rig "column" investigating the material MD2 


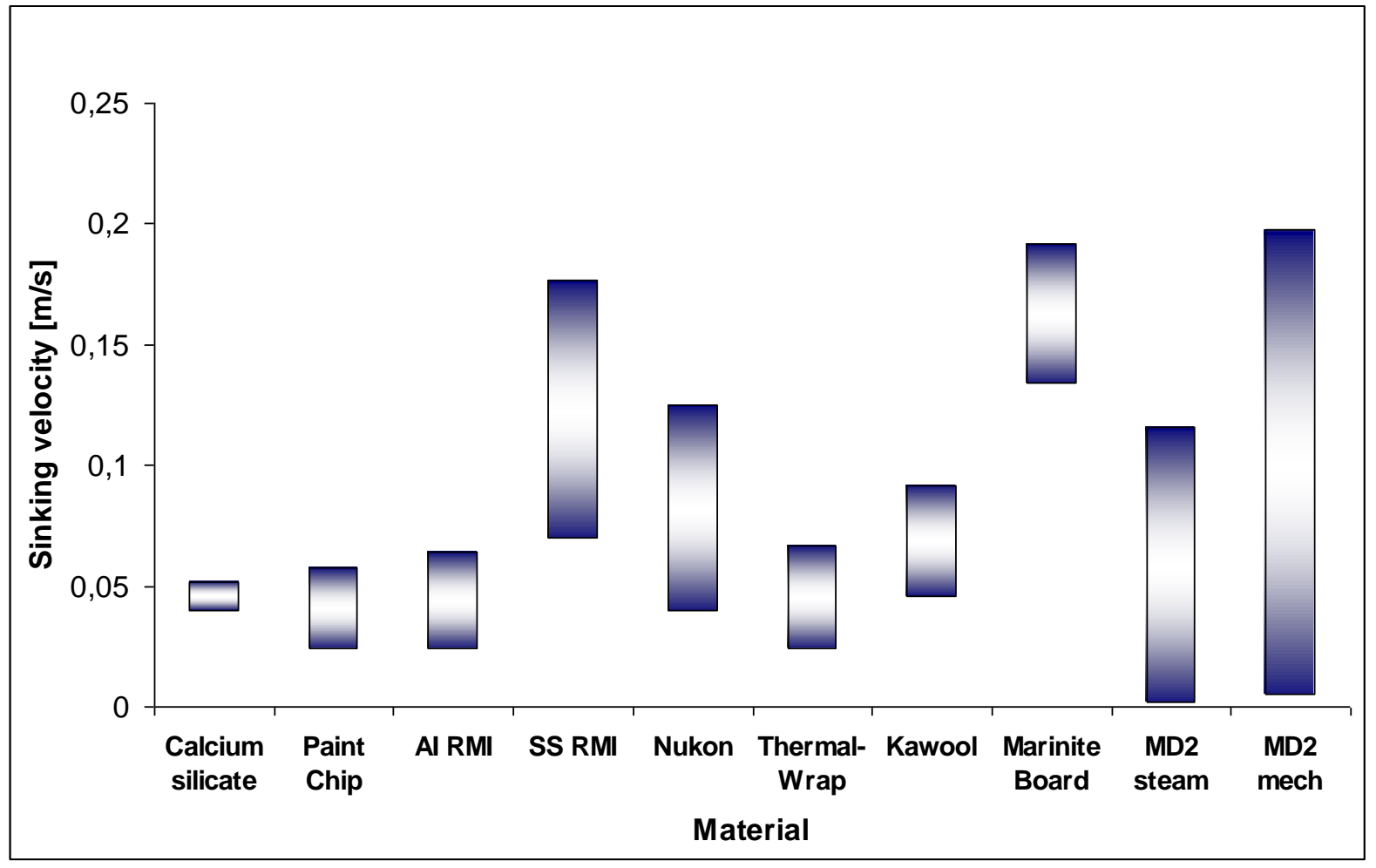

Fig. 2: Comparison of measured sinking velocities of the material MD-2 (last two columns) to published values of other insulation materials (NUREG/CR-6808) 


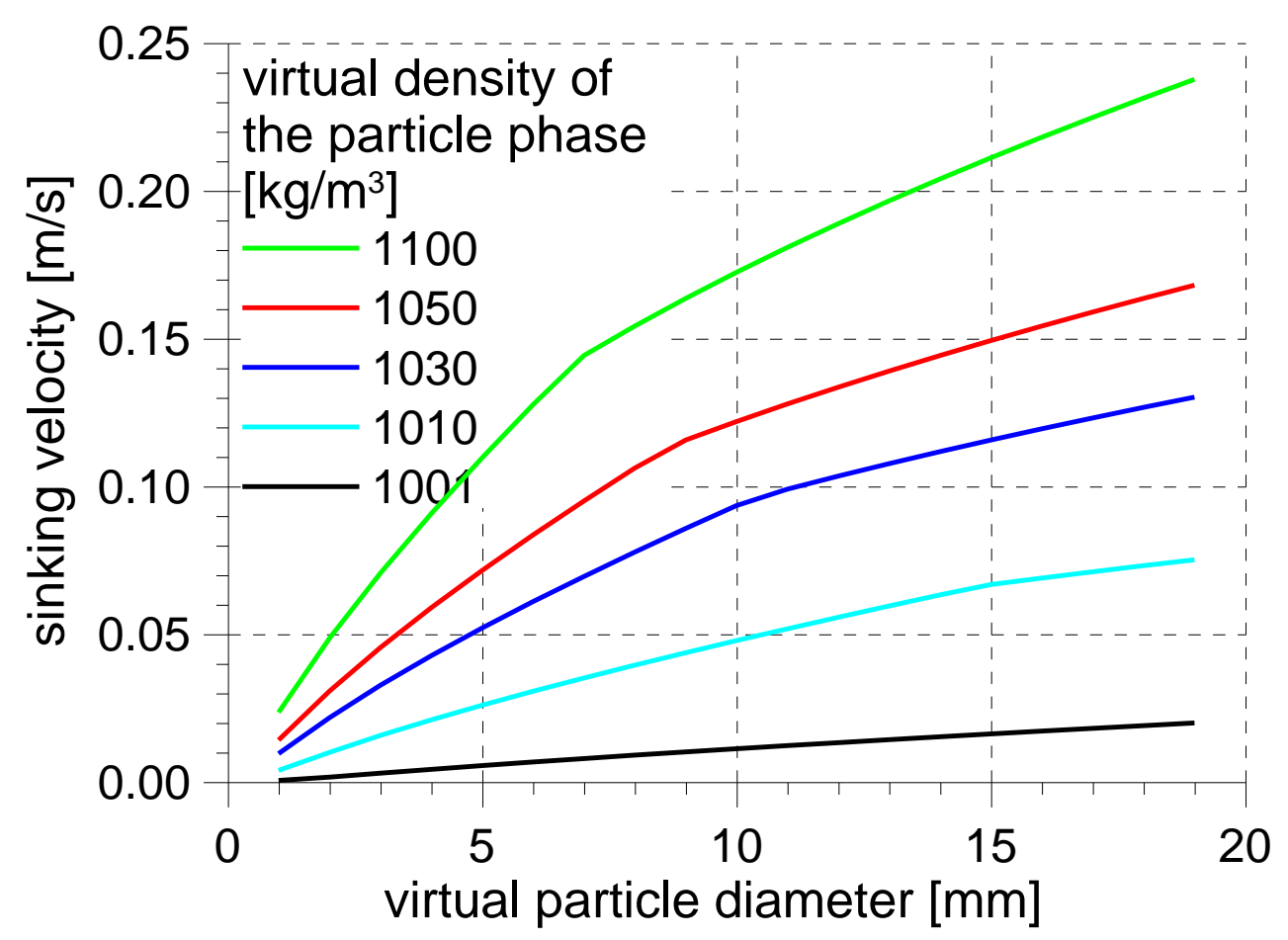

Fig. 3: Dependence of the sinking velocity on the virtual particle density and the virtual particle diameter 


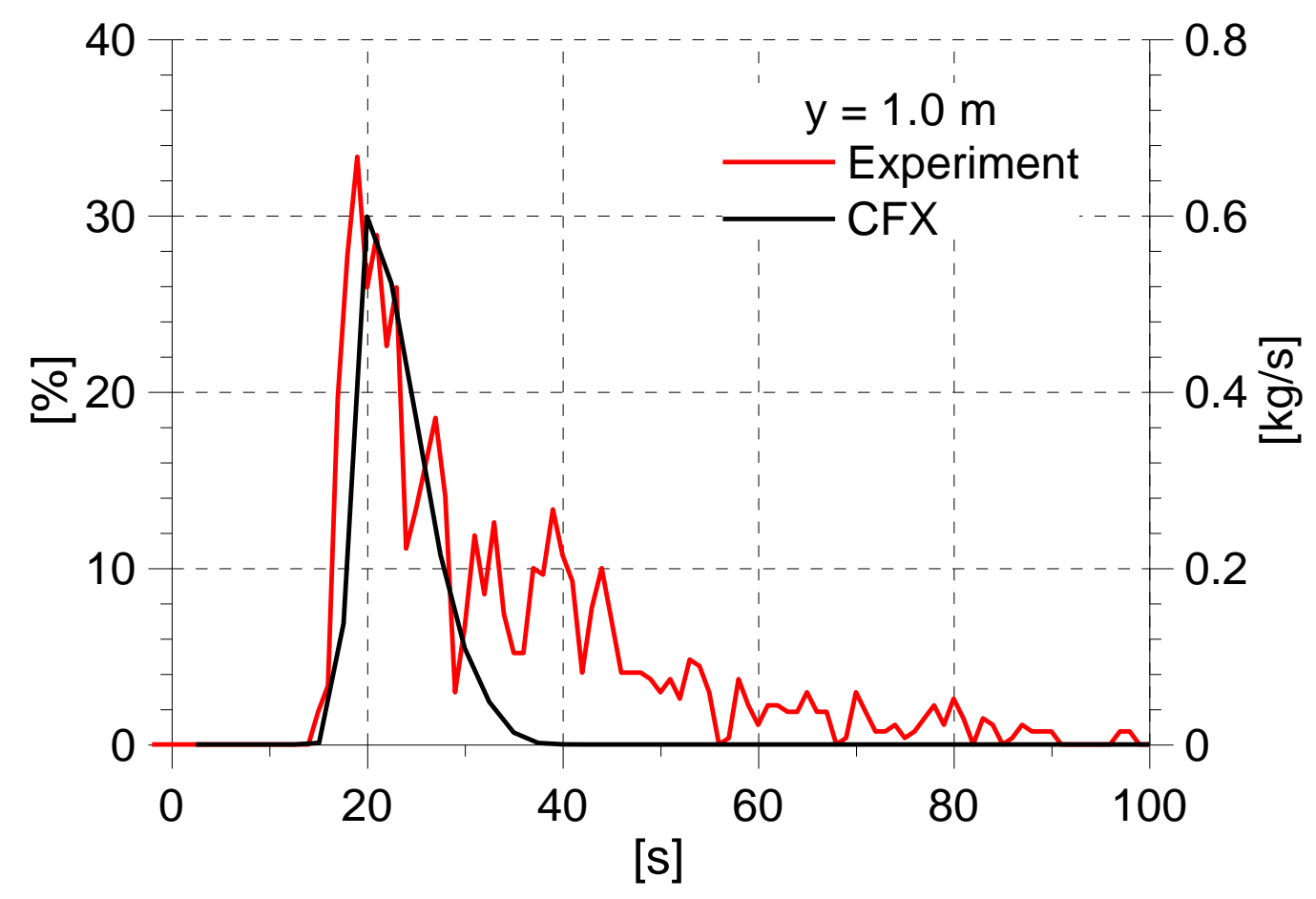

Fig. 4: Mass flow through a plane at the height level of $1 \mathrm{~m}$ 


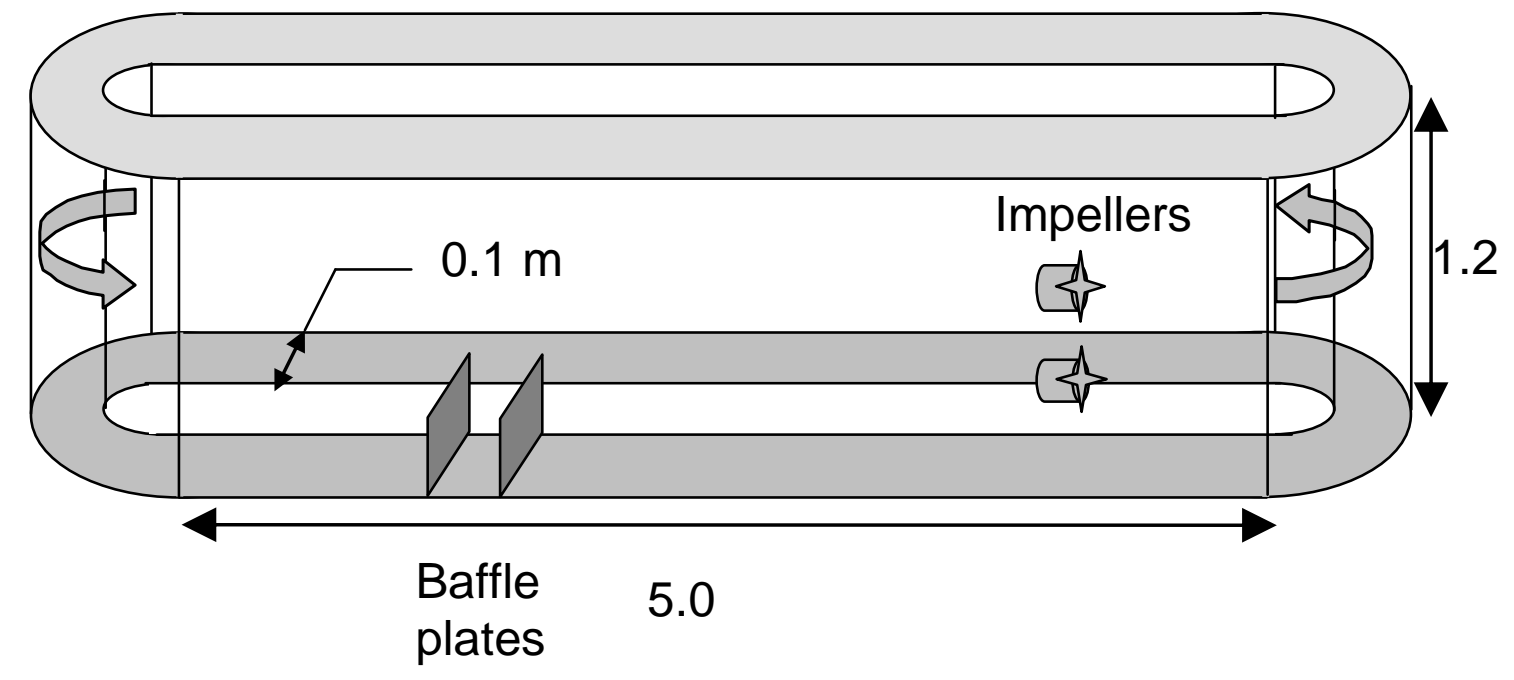

Fig. 5: Channel for investigation of the deposition and re-suspension properties 


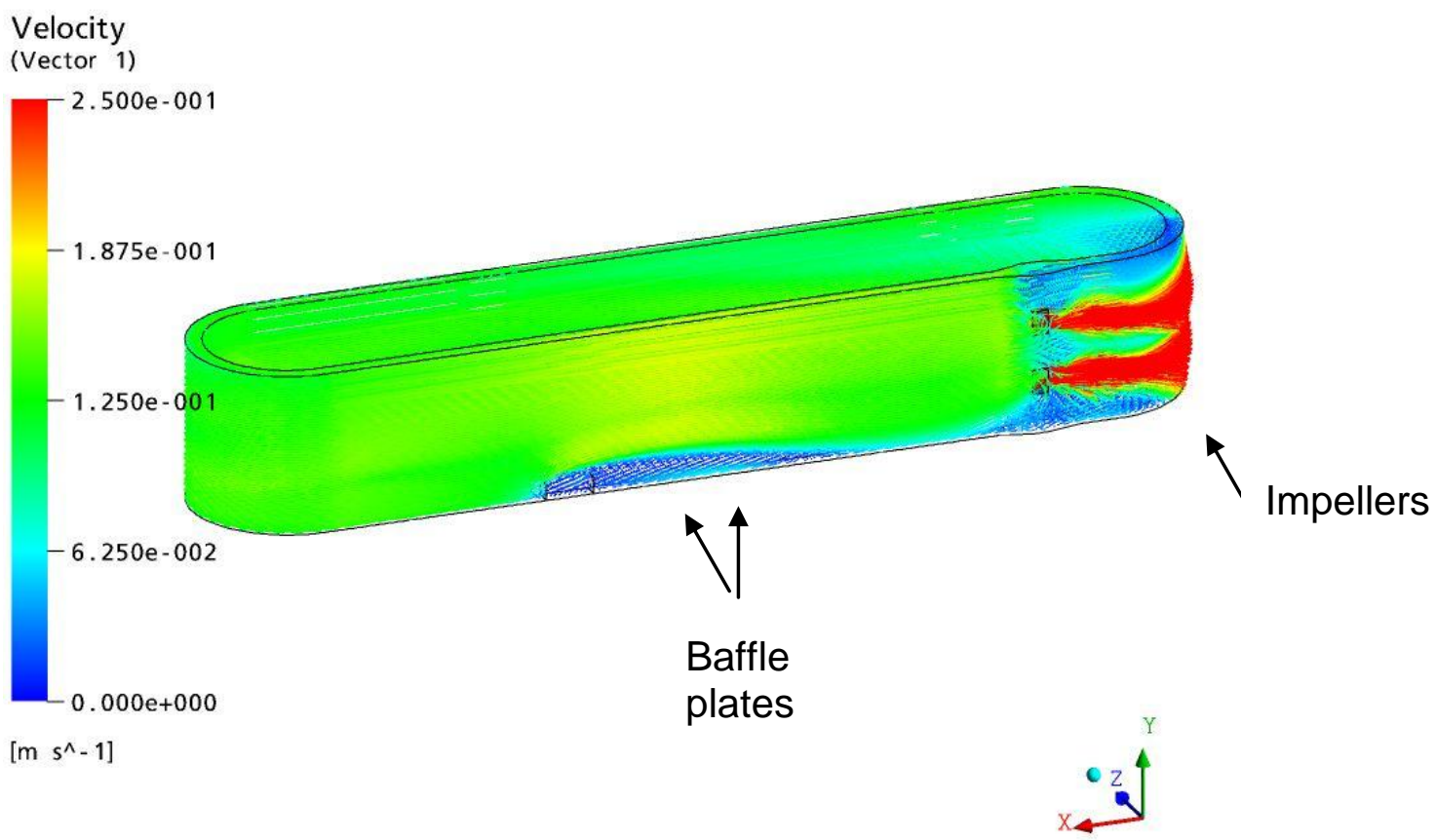

Fig. 6: Calculated velocity field in the test rig "channel" with baffle plates 

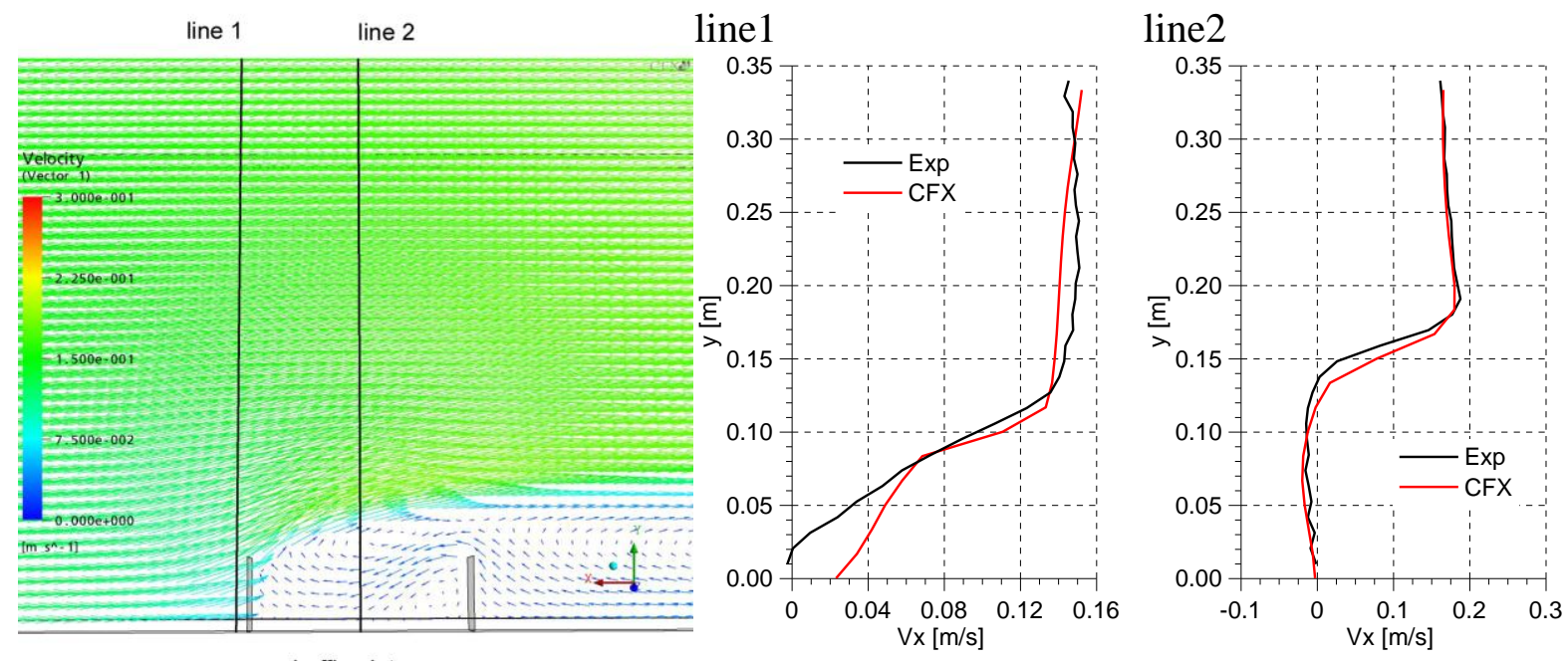

Fig. 7: Calculated flow field near the baffle plates (flow direction from left to right) and comparison of measured and calculated velocity profiles 


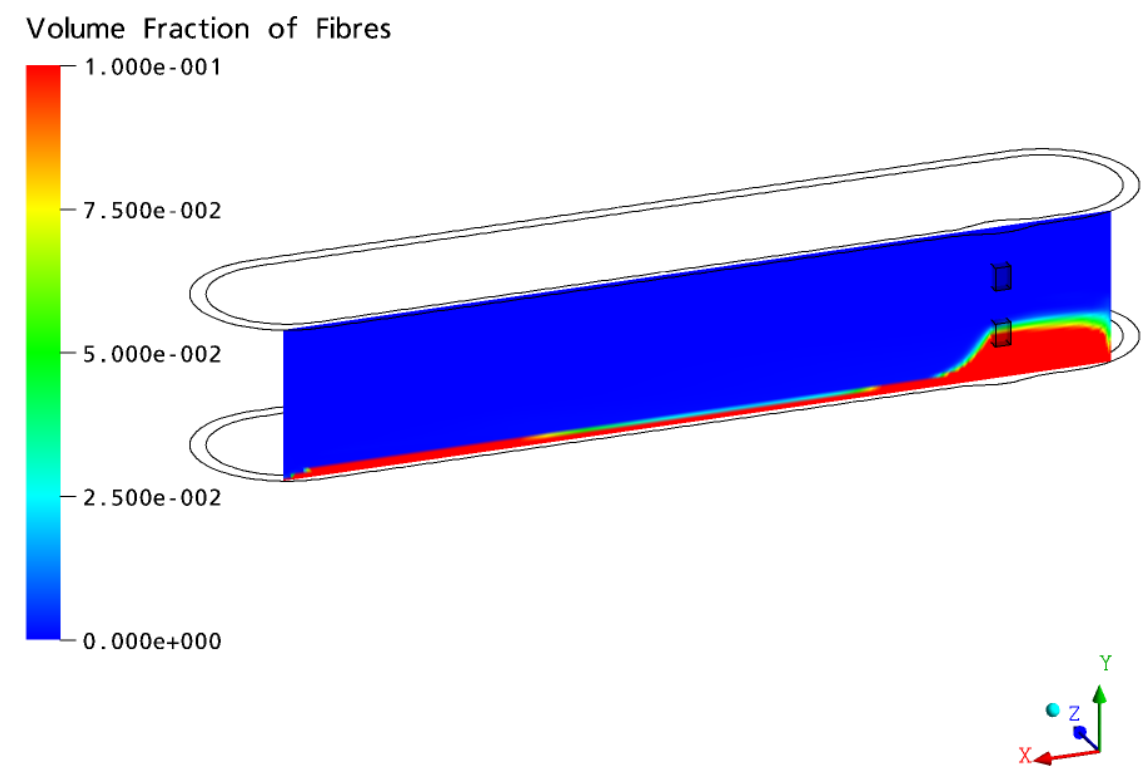

Fig. 8 Calculated fibre distribution in the channel without consideration of turbulence dispersion $($ Vwater $=0.5 \mathrm{~m} / \mathrm{s}$ ) 


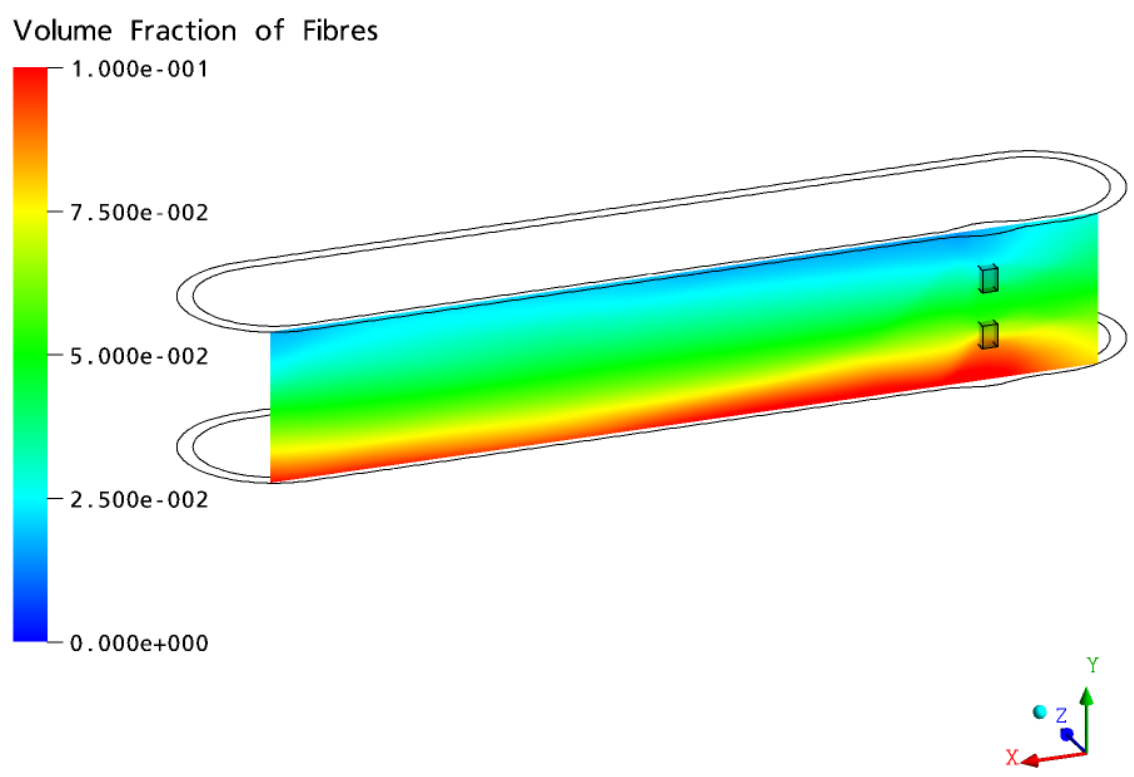

Fig. 9 Calculated fibre distribution in the channel considering of turbulence dispersion according eq. (10) with $\mathrm{C}_{\mathrm{TD}}=250$ 


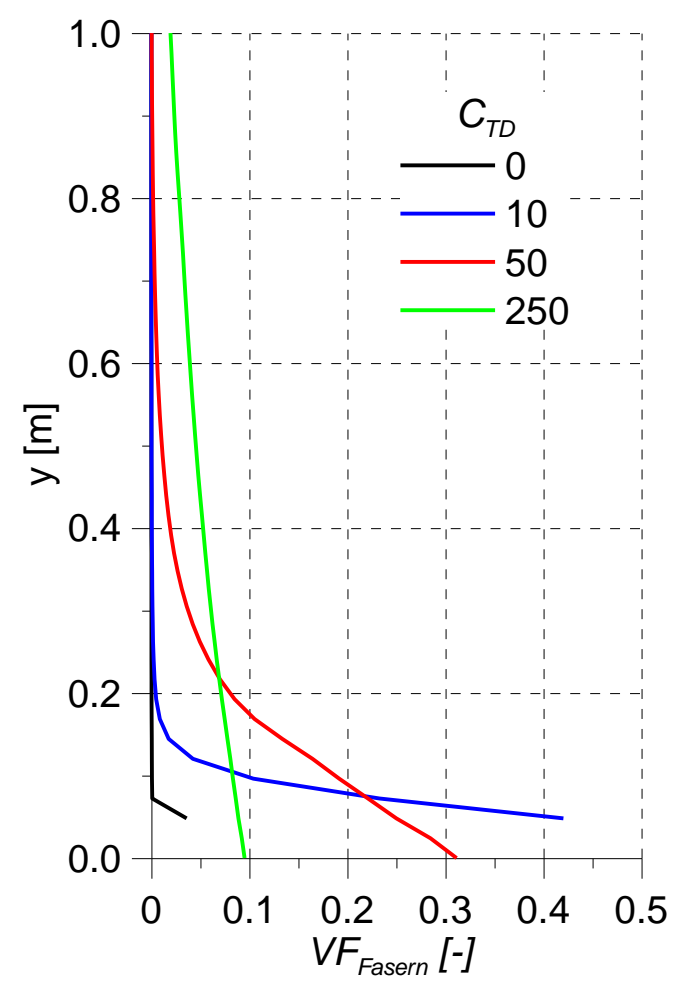

Fig.10: Calculated dependence of the vertical fibre volume fraction profile on $C_{T D}$ 


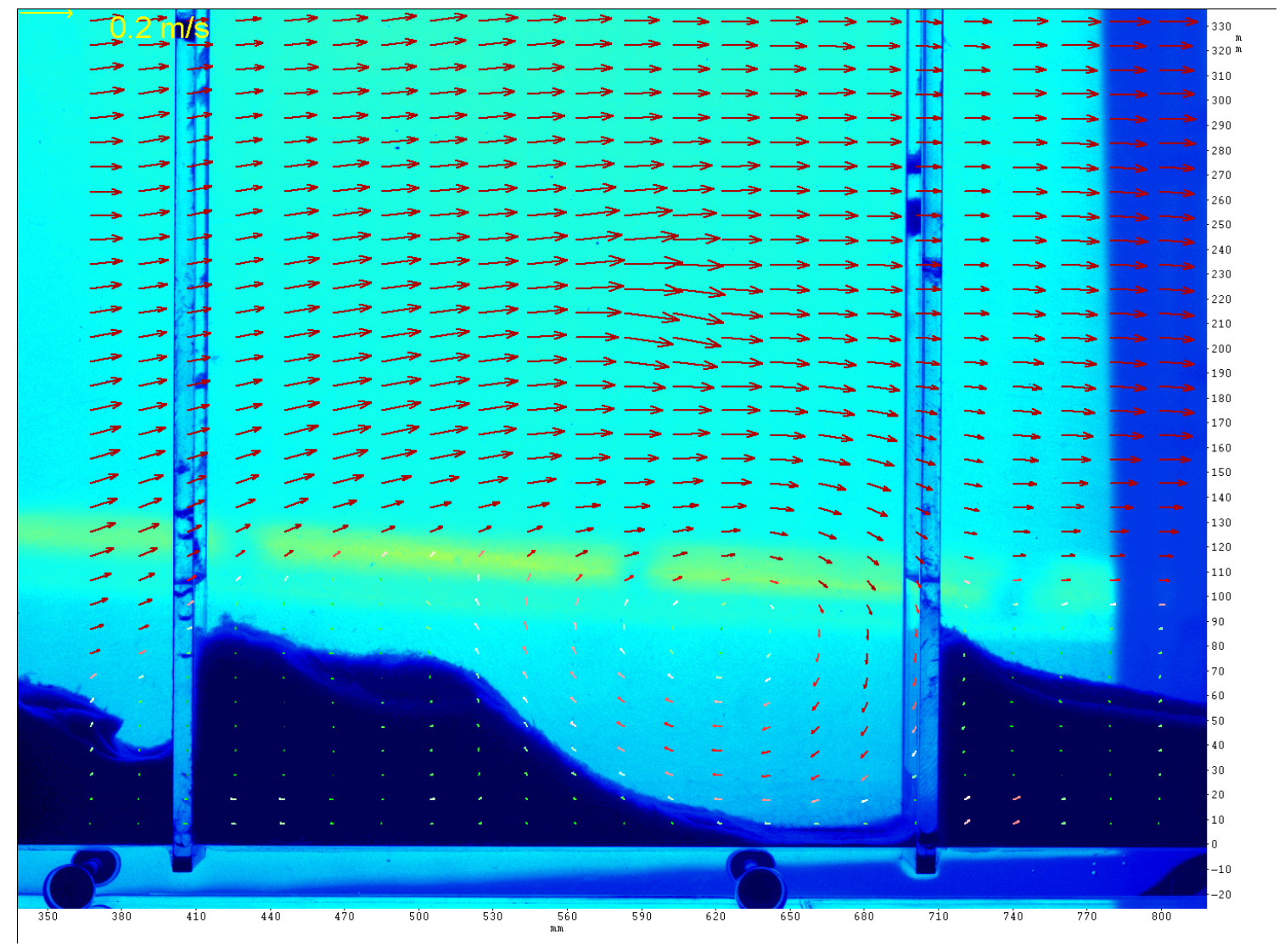

Fig. 11: Laser PIV measurements of the velocity field and the fibre distribution between two dams 


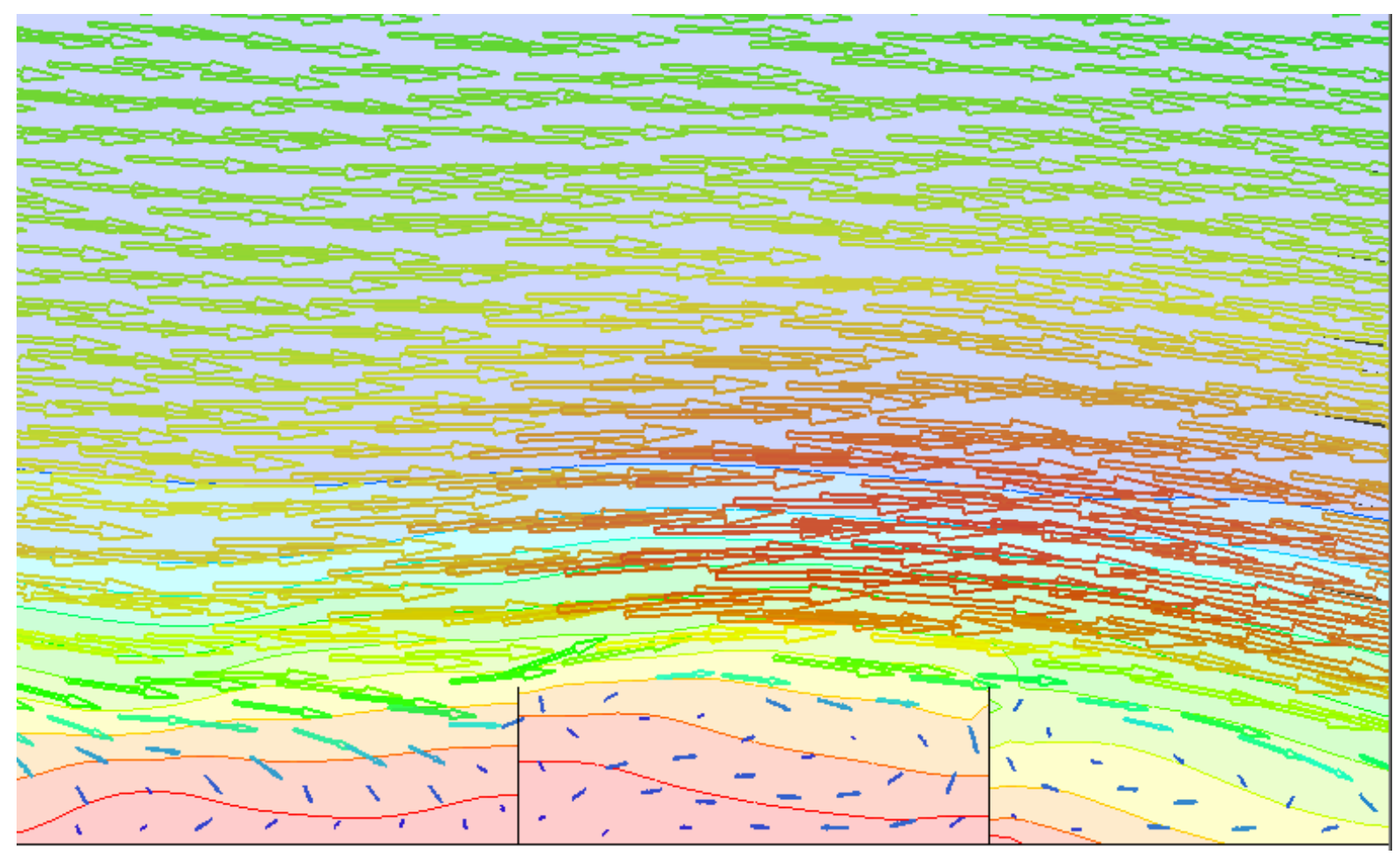

Fig. 12: Calculated water velocity field (red vectors $\sim 0.20 \mathrm{~m} \mathrm{~s}^{-1}$ ) and fibre distribution (red fraction was 0.5 ) for the viscosity models of equation (28), applying the Euler/Euler approach using the CFD code ANSYS CFX 


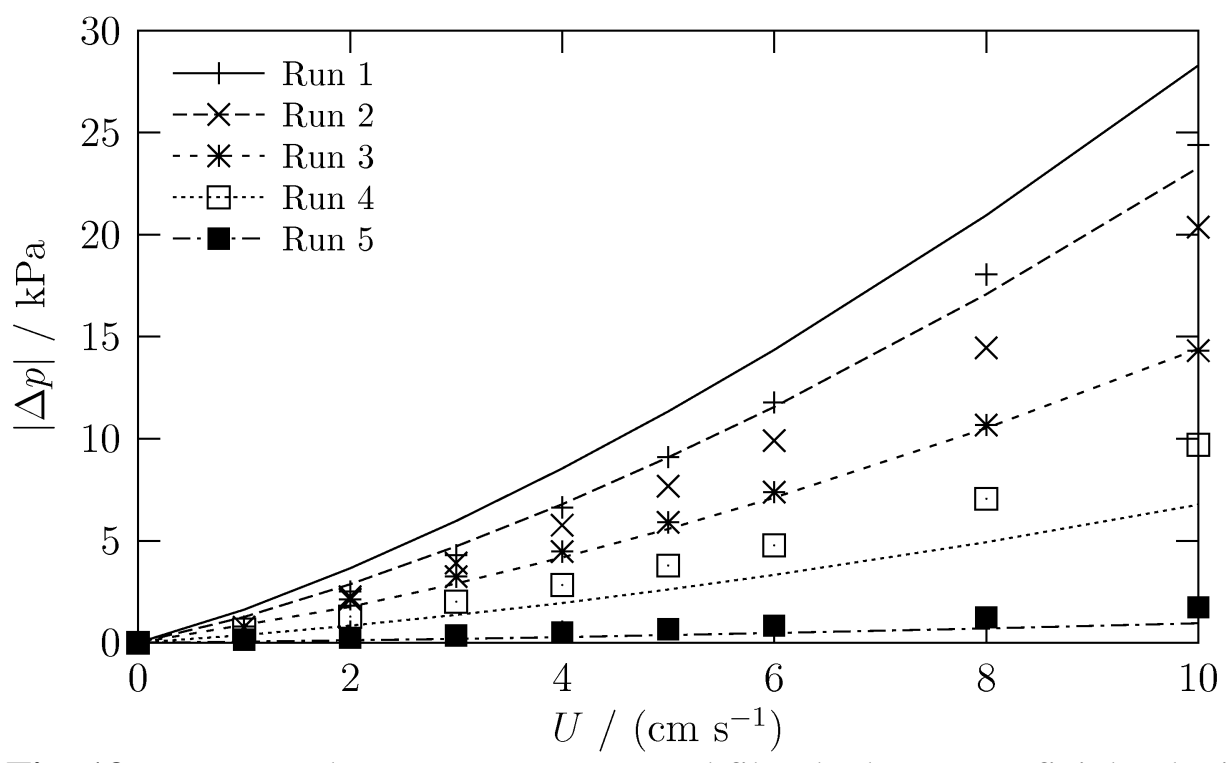

Fig. 13: Pressure drop across compressed fibre bed vs. superficial velocity at different experimental conditions (strainer mass load, fluid properties), experiments (points), computed profiles (lines) 


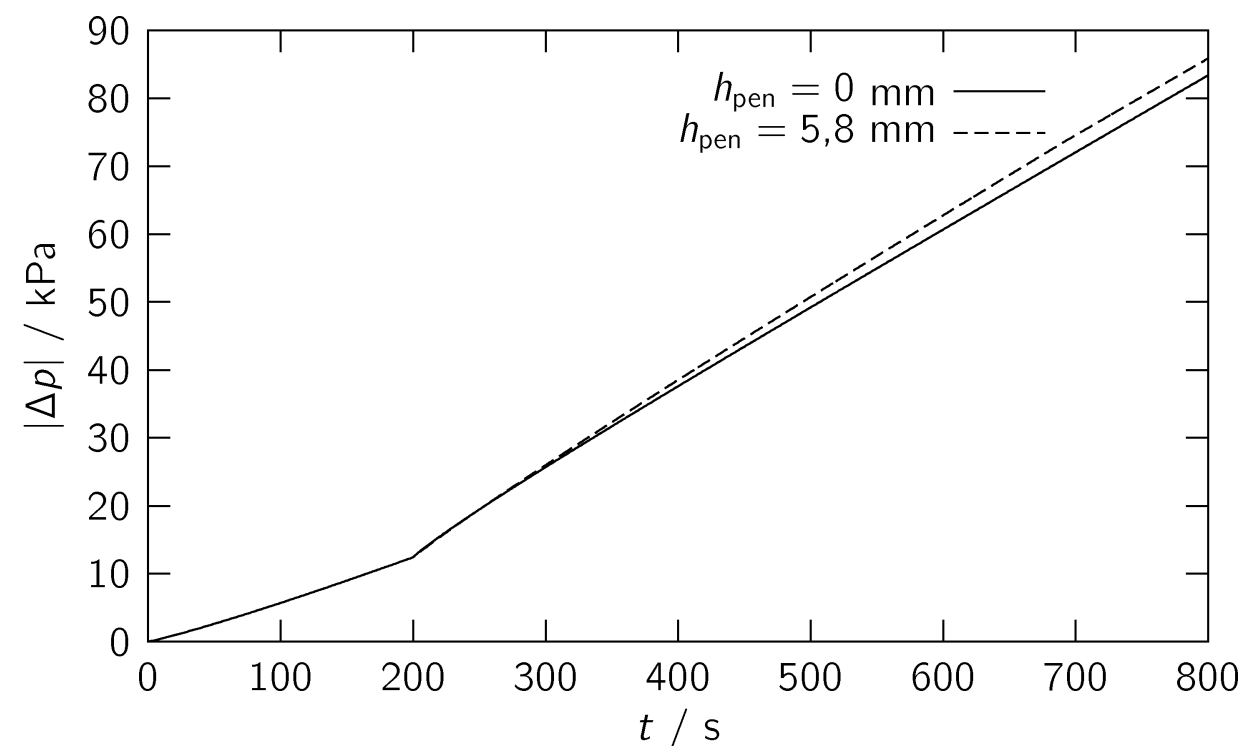

Fig. 14: Pressure drop build-up at composed beds; superficial velocity $U=6 \mathrm{~cm} / \mathrm{s}$, accumulation of fibres for $0<\square \mathrm{t}<200 \mathrm{~s}$, sludge particle deposition for $200 \mathrm{~s}<\mathrm{t}<800$ $\mathrm{s}$, different penetration depths $\mathrm{h}_{\text {pen }}$ 


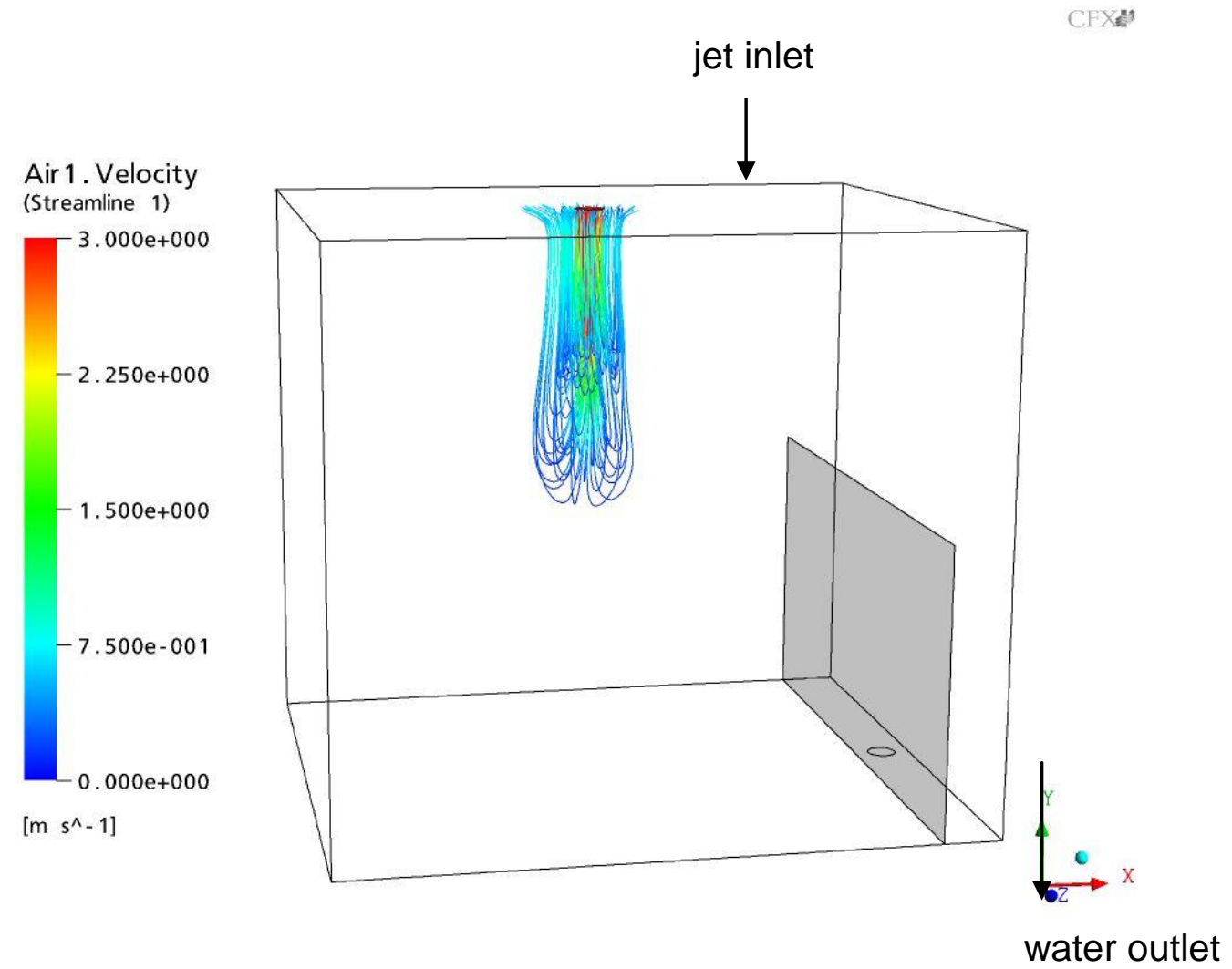

Fig. 15: CFD simulation of the jet experiment 


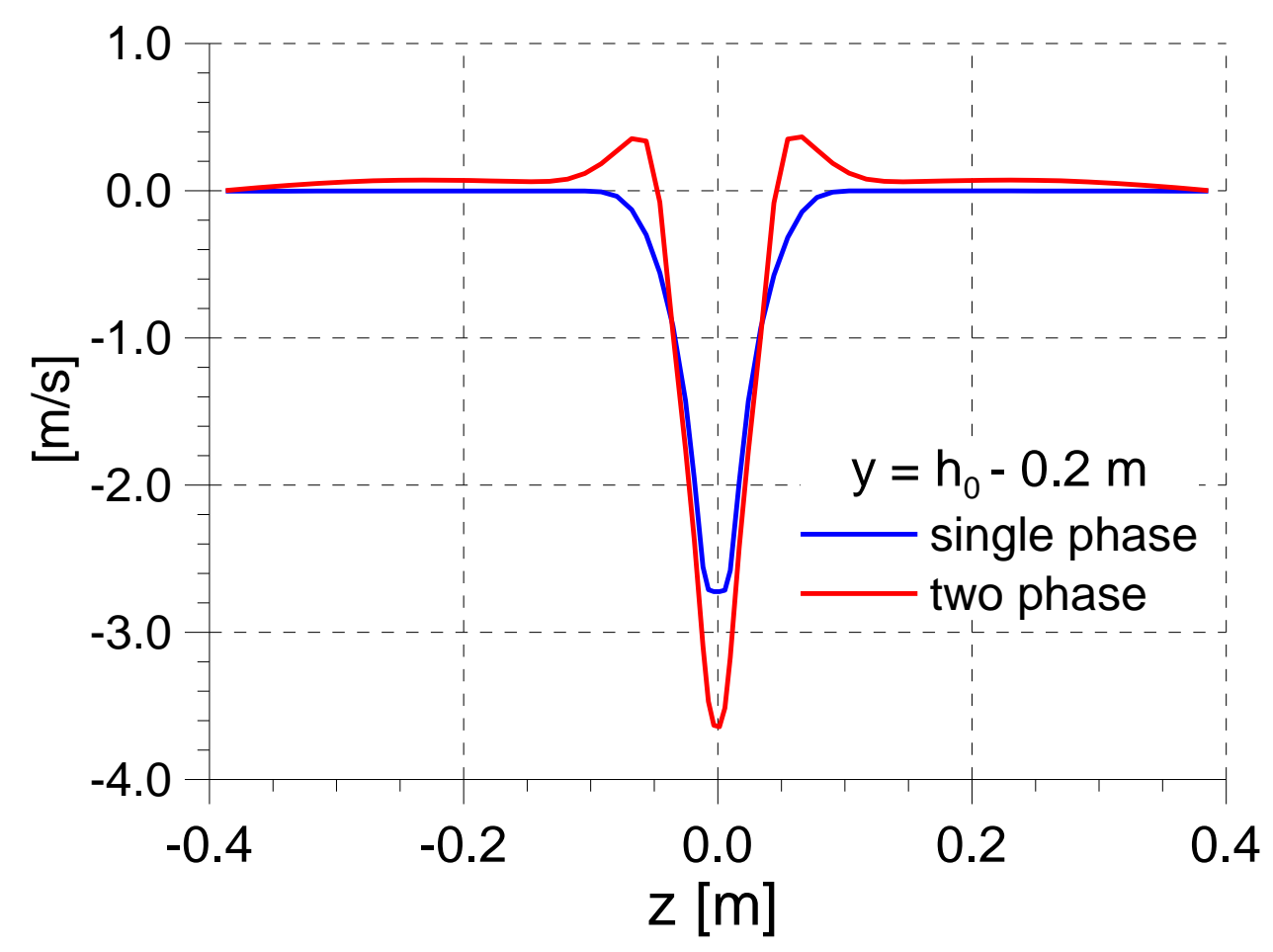

Fig. 16 Influence of the air entrainment on the liquid velocity profile 

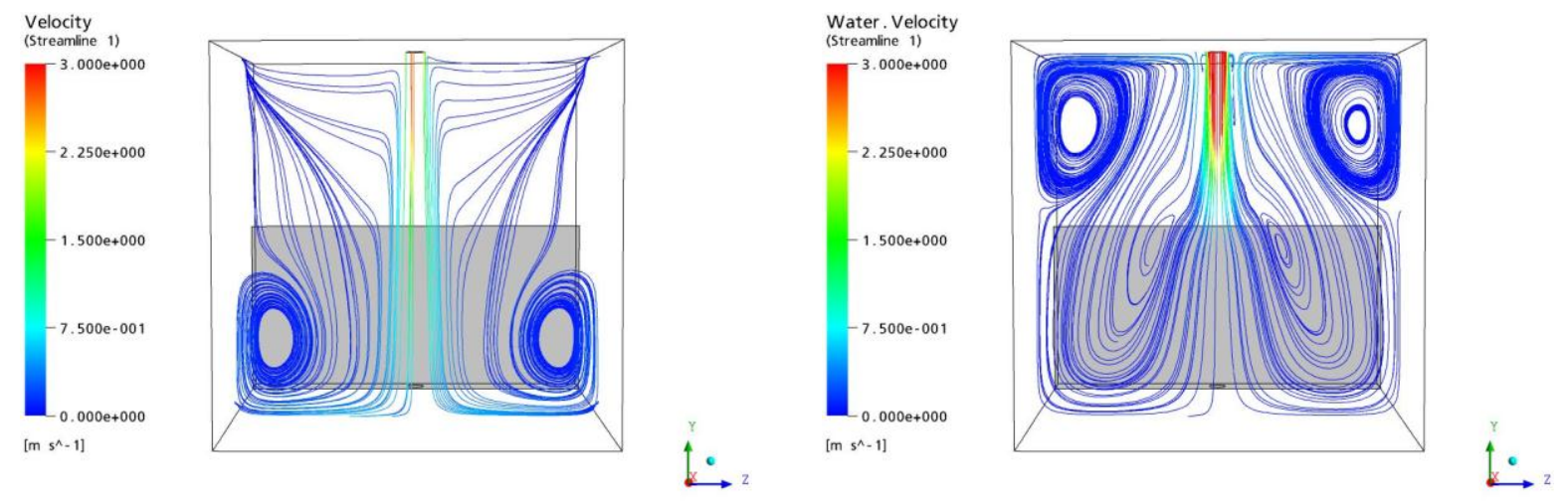
a) single phase jet
b) two phase jet

Fig. 17 Influence of the entrained gas on the flow field 
TABLES

\begin{tabular}{|lllll|}
\hline Table 1: Experimental conditions \\
\hline Run & $N_{S} / \mathrm{kg} \mathrm{m}^{-2}$ & $T /{ }^{\circ} \mathrm{C}$ & $\rho_{c} / \mathrm{kg} \mathrm{m}^{-3}$ & $\mu_{c} / \mathrm{mPa} \mathrm{s}$ \\
\hline 1 & 6.01 & 44.5959 & 990.44 & 0.601 \\
2 & 6.01 & 59.0055 & 983.69 & 0.474 \\
3 & 3.87 & 58.8505 & 983.77 & 0.475 \\
4 & 1.96 & 59.6812 & 983.35 & 0.469 \\
5 & 0.32 & 59.6948 & 983.34 & 0.469 \\
\hline
\end{tabular}

